\title{
Assessment of Extreme Wave Impact on Coastal Decks with Different Geometries via the Arbitrary Lagrangian-Eulerian Method
}

\author{
Tao Xiang ${ }^{1}$ and Denis Istrati $2, *$
}

1 Department of Civil Engineering, Stony Brook University; xiang.tao.xt1118@gmail.com

2 Department of Civil and Environmental Engineering, University of Nevada, Reno, NV 89557, USA;

* Correspondence: distrati@unr.edu

\begin{abstract}
Given the documented wave-induced damage of elevated coastal decks during extreme natural hazards (e.g. hurricanes) in the last two decades, it is of utmost significance to decipher the wave-structure-interaction of complex deck geometries and quantify the associated loads. Therefore, this study focuses on the assessment of solitary wave impact on open-girder decks that allow the air to escape from the sides. To this end, an arbitrary Lagrangian-Eulerian (ALE) numerical method with a multi-phase compressible formulation is used for the development of three-dimensional hydrodynamic models, which are validated against a large-scale experimental dataset of a coastal deck. Using the validated model as a baseline, a parametric investigation of different deck geometries with a varying number of girders $\mathrm{Ng}$ and three different widths, was conducted. The results reveal that the $\mathrm{Ng}$ of a superstructure has a complex role and that for small wave heights the horizontal and uplift forces increase with the $\mathrm{Ng}$, while for large waves the opposite happens. If the $\mathrm{Ng}$ is small the wave particles accelerate after the initial impact on the offshore girder leading to a more violent slamming on the onshore part of the deck and larger pressures and forces, however, if $\mathrm{Ng}$ is large then unsynchronized eddies are formed in each chamber, which dissipate energy and apply out-of-phase pressures that result in multiple but weaker impacts on the deck. The decomposition of the total loads into slamming and quasi-static components, reveals surprisingly consistent trends for all the simulated waves, which facilitates the development of predictive load equations. These new equations, which are a function of $\mathrm{Ng}$ and are limited by the ratio of the wavelength to the deck width, provide more accurate predictions than existing empirical methods, and are expected to be useful to both engineers and researchers working towards the development of resilient coastal infrastructure.
\end{abstract}

Keywords: wave-structure-interaction; storm; hurricane; waves; loads; pressures; slamming; decks; bridges; CFD

\section{Introduction}

In coastal regions transportation networks are often exposed to catastrophic waves during storms, hurricanes or tsunamis. For example, hurricane Katrina (2005) and the 2004 and 2011 tsunamis in the Indian Ocean and Japan respectively, caused damage to numerous coastal jetties, wharves, bridges and roads, and unprecedented economical loses [14]. Based on post-event damage assessment data to transportation assets from recent tsunamis, Williams et al. [5] pointed out that bridges are more vulnerable to the impact of tsunami waves than roads. Since coastal bridges act as lifelines that enable the evacuation and rescue of vulnerable communities after extreme events, the survival of such infrastructure is a critical need. Despite the development of several predictive wave load equations in recent years (e.g. [6-10]) the majority of them were calibrated with datasets from specific deck types, making it hard to find a set of universal equations that can be applied 
to other deck configurations and geometries outside the original dataset. Therefore, it became necessary to understand the effects of extreme waves on a wider range of coastal decks, and to develop accurate methodologies for the prediction of the applied loads.

In the early twentieth century, experimental methods were utilized to investigate the wave forces on structures. El Ghamry and Osman [11] conducted experiments to test the wave force on a flat plate, and developed a relationship between the wave period, wave steepness and plate elevation. French [12] studied the solitary wave-induced pressures on a horizontal platform located above the still water level, and revealed the existence of two characteristic components: a short-duration impact pressure and a slow-varying one. These two components were also observed by Overbeek and Klabbers [13] in the hurricane-induced vertical wave forces on jetties. Wang [14] experimentally studied the vertical forces on a horizontal plate subjected to periodic waves and explained the physics of the impact process. Robertson et al. [15] surveyed the damaged bridges and buildings along the Gulf Coast in Louisiana, Mississippi and Alabama after hurricane Katrina. They analyzed the effects of the hurricane waves into a lateral load, hydrostatic and hydrodynamic uplift, scour and debris effects, and conducted analytical calculations to explain the observed damage. More recently, Bradner et al. [16] presented a large-scale experimental study of a reinforced concrete bridge deck subjected to regular and irregular waves. Guo et al. [17] used the eigenfunction expansion method and presented an analytical method to estimate of maximums of horizontal and vertical wave forces on submerged bridge decks impacted by hurricane waves. The analytical equations were compared with largescale experimental data, demonstrating their accuracy. Nakamura et al. [18] conducted both hydraulic experiments and numerical simulations to study the tsunami wave forces on bridge superstructures, and concluded that using Morison's equation it was possible to estimate the horizontal force.

Istrati [19] conducted hydrodynamic experiments of both solitary waves and bores impacting a single-span 1:5 scale bridge deck with different configurations, including open-girder and box-girders decks supported on steel or elastomeric bearings and a substructure with varying levels of flexibility. The experimental results revealed the significant dependence of both the total applied forces and the uplift demand in individual structural components (bearings and columns), on the deck type and the flexibility of the structural system, as well as, the wave type [19-20]. Moreover, box-girder bridges were also investigated experimentally under regular waves in [21], and appropriate simplified load equations were developed. Although the majority of the studies focused on the maximum horizontal and vertical forces, some of them [22-24] demonstrated the governing effect of the overturning moment on the demand in individual connections, which results in concentration of the uplift in the offshore bearings, increasing consequently the probability of failure. To account for the complex temporal evolution of the fluid-induced forces and moment, Istrati et al [23] developed a simplified physics-based design methodology that considers three load cases. A similar approach of using multiple load cases in the design of coastal decks subjected to storms has also been used in AASHTO [25]. An alternative method for calculating the design values for individual elastomeric bearings that connect the deck to the substructure, is to use non-dimensional design curves, as the ones provided in [26]. It is noteworthy that in addition to wave loads on decks and connections, more recently some studies have investigated the hydrodynamic loads on columns, bridge piers and pile caps [27-29], while others have focused on the resilience assessment of coastal bridges [30] and drag-induced displacements of bridge spans exposed to hurricanes [31].

Apart from the experimental studies conducted to date (e.g. [11-14], [16], [18-23], [32]), the development of numerical solvers and the increased availability of high performance computing (HPC) resources provided an alternative efficient methodology for studying further the wave forces on coastal structures. Huang and Xiao [33] applied the Reynolds averaged Navier-Stokes (RANS) equations with the volume of fluid (VOF) method to investigate the dynamic impact of waves on the bridge deck over the I-10 Es- 
cambia bay. The research found out that the major reason for the damage caused by hurricane Ivan was the large wave-induced uplift, which exceeded the weight of the deck. Istrati and Buckle [34] conducted fluid-structure-interaction (FSI) analyses to study the flexibility of both the superstructure and the connections during the tsunami impact on a simplified two-dimensional bridge model and pointed out the importance of structural dynamics and FSI for predicting both the applied loads and the reactions forces. Similarly, $\mathrm{Xu}$ and Cai [35] considered the horizontal flexibility of the bridge via a single-degree of freedom numerical model, and found out that the increase of this flexibility resulted in larger horizontal forces on the superstructure due to dynamic amplification. Moreover, Cai et al. [24] applied a dynamic mesh updating technique to study the behavior of a bridge superstructure under the impact of solitary waves. The model simulated the bridge response and showed that the rotational movement and vertical translation affected the magnitude of the vertical wave force. Matamoros et al [36] validated a coupled EulerianLagrangian finite element model and showed that for waves similar to those from past hurricanes in the Gulf Coast, the deck with flexible connections witnessed larger connection forces. Greco et al. [37] used a moving mesh method to simulate the extreme fluid impact on bridge deck structures. Their computations took into account the bridge deformability, and pointed out that the force coefficients provided by the codes need to be revised. Based on numerical simulations of solitary waves, Xiang et al. [10] quantified numerically the influence of wave height and deck elevation on the quasi-static and slamming force components and developed an improved predictive equation that can capture not only the forces but also the moment. While all the majority of numerical investigations to-date were based on mesh-based methods (e.g. [10], [24], [33-38]), some recent studies used (i) particle-based methods, such as, the Smoothed Particle Hydrodynamics (SPH), [39-41], and (ii) hybrid or coupled particle-mesh-based methods, such as, the particle finite-element method (PFEM) [42] and the coupled SPH-FEM [43], to investigate the complex wave-structure interaction or wave-debris-structure interaction, and loads on coastal structures.

While the majority of the numerical studies focused on two-dimensional (2D) models, some of them pointed out that the interaction between a deck and the wave is not a completely two-dimensional process, especially when (i) the deck has diaphragms that trap the air [44-46], (ii) the elevated slab has air-vents [19], (iii) the deck is skewed [47-49] (iv) the wave is oblique [49], or (v) water-borne debris is trapped in front of the deck at an off-center location [50]. For example, Bozognia and Lee [44] showed that simplified 2D simulations of periodic waves impacting a concrete deck with diaphragms, could not represent the motion of air in the longitudinal direction. The accuracy of the predictions could be significantly improved by simulating the airflow under the deck in three-dimensions (3D). The importance of 3D effects was also observed experimentally in the case of bridges with air-vents in the deck, for which case the distance of the vents from (i) the diaphragms and (ii) the girders forming the chambers had a critical role [19]. Moreover, Crowley et al. [45], who conducted numerical simulations of monochromatic wave impact on bridge decks noticed that both the high-frequency load component and the quasi-static component are affected by trapped air, and that 3D simulations can capture the air movement more realistically than the $2 \mathrm{D}$ ones.

As discussed above, elevated coastal decks of different shapes and under different wave conditions have been studied in recent years, however, only a few of these studies investigated the role of the number of girders $(\mathrm{Ng})$ on the applied loads. Hayatdavoodi et al [51] studied numerically the effect of $N g$ by modeling the impact of solitary waves on a small-scale (1:35) flat plate and an open-girder deck with $N g$ between two and six. They concluded that the increase of $\mathrm{Ng}$ increases slightly the horizontal force, but has no effect on the vertical force. Similarly, using the SPH method Sarfaraz and Pak [41] found that when the deck is submerged, the $\mathrm{Ng}$ has no effect on the uplift forces. On the other hand, for elevated decks they revealed that the largest uplift was witnessed by the deck with two and three girders, and that for a larger $\mathrm{Ng}$ the girders can act as barriers that decrease the pressure on the bottom of the deck. Furthermore, Moideen et al. [52] demonstrated 
numerically via the RANS method that the solitary wave-induced forces on a deck with girders is larger than the ones on a flat plate. By investigating three decks with $N g=4,5$ and 6, they concluded that for small air-gaps the $\mathrm{Ng}$ has a negligible effect, however, as the air gap increases, i.e. the deck relative elevation increases, the increase of $\mathrm{Ng}$ increases significantly the uplift force.

The significant differences in the findings of the aforementioned three studies [41], [51-52] could be attributed to a variety of reasons, such as, differences in deck dimensions, hydrodynamic conditions, modeling assumptions (e.g. single-phase vs. multi-phase) and potential scale-effects in small-scale models. Nonetheless, these findings demonstrate the complex effect of the number of girders $(\mathrm{Ng})$ on the wave loads, and its dependence on the wave conditions. Therefore, the objective of the current research study is to advance the fundamental understanding of solitary wave impact on coastal decks with a different number of girders and deck widths, and to develop simplified load equations that will account for the role of these two parameters. The focus of the particular paper will be on open-girder decks with cross-frames, where the air can escape from the sides of the span. The first part of the paper will focus on the validation of an arbitrary Lagrangian-Eulerian (ALE) formulation with large-scale experimental data, the second part will present a parametric investigation of the role of the two aforementioned parameters, and the third part will develop improved predictive equations for wave loads.

\section{Numerical Modeling}

\subsection{Governing Equations and Validation}

The numerical investigation was conducted using the finite element analysis code LS-DYNA [53]. The interaction between the water, the air and the bridge deck is computed using an ALE formulation [54]. The equilibrium equations for mass, momentum and energy are given by equations (1), (2) and (3) respectively:

$$
\begin{gathered}
\frac{\partial \rho}{\partial t}+\rho \operatorname{div}(v)+(v-w) \operatorname{grad}(\rho)=0 \\
\rho \frac{\partial v}{\partial t}+\rho \operatorname{div}(v)+\rho(v-w) \operatorname{grad}(v)=\operatorname{div}(\sigma)+f \\
\rho \frac{\partial e}{\partial t}+\rho \operatorname{div}(e)+\rho(v-w) \operatorname{grad}(e)=\sigma: \operatorname{grad}(v)+f \cdot v
\end{gathered}
$$

where $v$ is the particle velocity, $w$ is the grid velocity of the numerical simulation, $\rho$ is the density of the material, $f$ is the body force and $e$ is the internal energy. $\sigma$ denotes the Cauchy stress which is given by:

$$
\sigma=-P I+\mu\left[\operatorname{grad}(v)+\operatorname{grad}(v)^{T}\right]
$$

where $P=$ the pressure; $I=$ the identity tensor; $\mu=$ the dynamic viscosity; $(v-w)=$ the convection velocity across the grid; and $T=$ matrix transpose.

Both the air and the fluid were simulated as compressible viscous fluids, with the viscosity being equal to $1.0 \mathrm{E}-5 \mathrm{~m}^{2} / \mathrm{s}$ for air and $0.001 \mathrm{~m}^{2} / \mathrm{s}$ for water. The compressibility of the fluid was controlled by the bulk modulus and was defined to be 1.0E5 and 2.2E9 Pa for air and water, respectively. Lastly, an equation of state with a linear polynomial form was used to determine the initial thermodynamic state of the material, as shown below. The pressure is given by:

$$
p=C_{0}+C_{1} \zeta+C_{2} \zeta^{2}+C_{3} \zeta^{3}+\left(C_{4}+C_{5} \zeta+C_{6} \zeta^{2}\right) E
$$

Where $C_{0-6}$ are user-defined constants, $E$ is the initial energy per initial volume, while the volumetric parameter is $\zeta$ equal to:

$$
\zeta=\frac{1}{V}-1
$$


with the relative volume $V=\rho_{o} / \rho$, where $\rho_{o}$ is the reference mass density. For more information the user can refer to Hallquist [53].

In order to validate the hydrodynamic solver, the large-scale (1:5) experimental study conducted by Istrati [17] in the $104 \mathrm{~m}$ long flume of the Hindsdale Wave Research Lab at Oregon State University, was used as a benchmark. In the experiments the bathymetry consisted of a $21.49 \mathrm{~m}$ long horizontal part at the wave-maker location, followed by a 1:12th sloped part $7.32 \mathrm{~m}$ long, and a second horizontal part $40.2 \mathrm{~m}$ long where the bridge was located, and another 1:12 slope towards the end of the flume, which dissipated the waves. However, in order to reduce the computational time, a smaller three-dimensional numerical flume was developed, which included the area close to the bridge location and was $27 \mathrm{~m}$ in length, $3.16 \mathrm{~m}$ in height and $0.3 \mathrm{~m}$ in depth, as shown in figure 1 . The bridge deck model was located at a distance of $15.79 \mathrm{~m}$ from the upstream boundary and $1.71 \mathrm{~m}$ from the bottom boundary. The span length was assumed to be $0.25 \mathrm{~m}$, meaning that a $0.05 \mathrm{~m}$ gap was left between the deck and the side walls of the flume to allow for the air to escape. The bridge deck model is rigidly fixed in all directions in order to restrain any translational and rotational movement.

The boundaries conditions of the computational domain include: no slip boundaries on the front, back, top and bottom sides; a damping section in the downstream area to prevent wave reflection; in the upstream boundary, an inlet velocity boundary is defined to generate targeted solitary waves. The time histories of the inlet velocity are pre-defined, according to the asymptotic long wave relationship, which is given as:

$$
u=\eta \sqrt{g / H}
$$

where $\eta$ represents the wave height time history, $H$ is the water depth, and $\mathrm{u}$ is the wave velocity. The mesh size of the ALE domain far from the bridge deck is $0.05 \mathrm{~m}$, while in the region of CDEF the mesh size of both the ALE domain and the bridge deck model is refined to $0.025 \mathrm{~m}$.

This experimental work was selected as a benchmark due to its extensive instrumentation that enabled the accurate quantification of both the hydrodynamic characteristics and the effects on the deck, including pressures at different locations on the girders and the slab, and forces measured by load cells at the interface between the superstructure and the substructure. For the current study, the experimental configuration with open chambers (i.e. cross-frames) and rigid connections, which was tested under the impact of four unbroken solitary wave heights and water depth of $1.16 \mathrm{~m}$, will be used. To verify the accuracy of the numerical method, the simulated wave profiles of SW1, SW2, SW3 and SW4, with corresponding heights equal to $H=0.43,0.52,0.68 \mathrm{~m}$ and $0.97 \mathrm{~m}$ are compared with the ultrasonic wave gauge measurements located at $0.92 \mathrm{~m}$ in front of the bridge deck . As shown in Figure 2, the numerically predicted wave profile histories agree well with the experimental data, both in terms of maximum values and temporal evolution, with some shape differences at the tail of the wave. These differences are more obvious for the large waves, e.g. SW3, and this could be due to the fact that in the experimental tests as the wave height increases the solitary wave undergoes a more significant shoaling process with nonlinear effects that change the shape of the wave. These effects cannot be captured in the truncated numerical model because the shoaling process is not simulated in the numerical model. Nonetheless, the solitary waves of the numerical model compare well with the modified solitary waves of the experiments, allowing us to proceed further with the comparison of the wave-induced effects on the deck. 


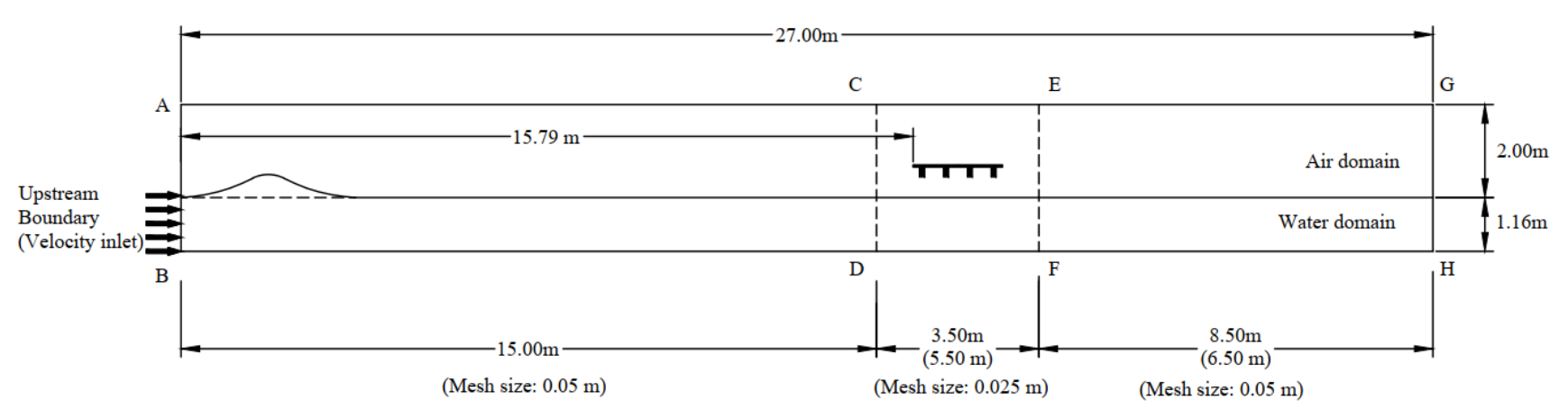

Figure 1. Layout of the computational domain
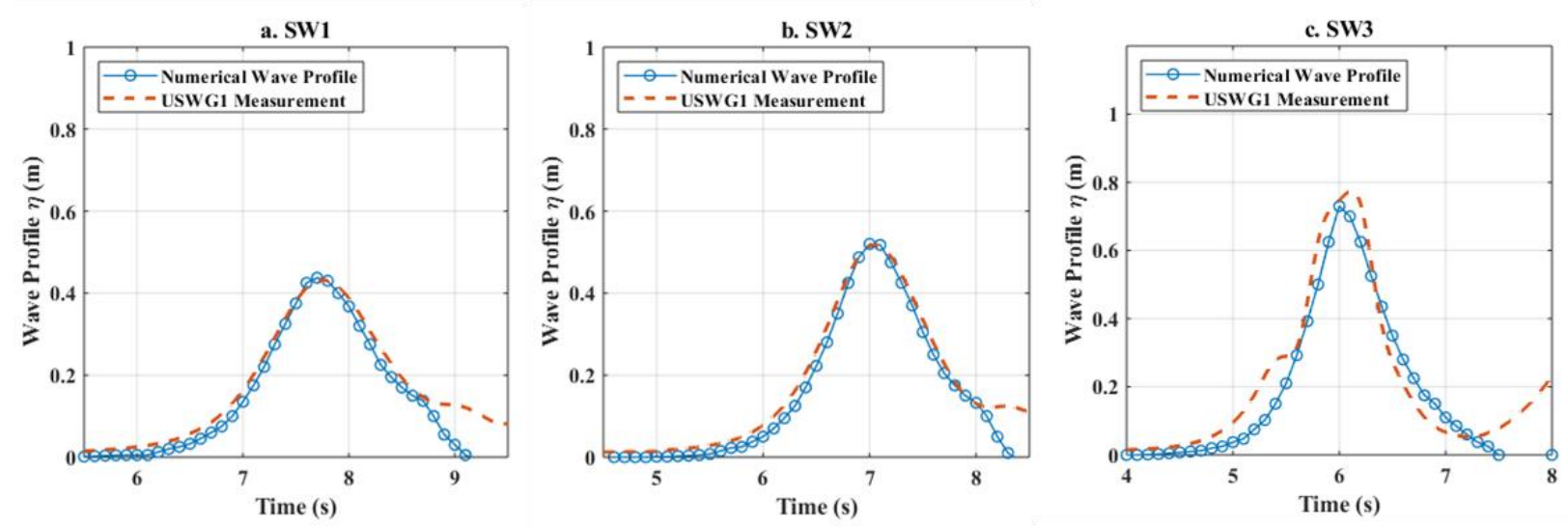

Figure 2. Comparison of wave profile at USWG1 between experimental measurements (source: Istrati [19]) and numerical simulations

To eliminate the effect of the structural dynamics on the measured forces, both the experimentally and numerically recorded force histories are filtered using a Butterworth filter (with cutoff frequency of $30 \mathrm{~Hz}$ ). The reason for choosing this filtering process has been thoroughly discussed in Xiang et al. (2020). Figure 3 shows a comparison of the horizontal and vertical wave force histories for SW3 and SW4. It can be observed that the maximum values of the numerical wave forces are close enough to the experimental measurements and the time histories are in reasonable agreement. Interestingly, the horizontal forces seem to be predicted more accurately than the vertical ones, with the worst prediction corresponding to the downward force (negative values in the $F_{Z}$ graphs). A possible reason for this observation is the fact that as mentioned previously the numerical model does not capture accurately the tail of the wave, which will affect the volume and the shape of the fluid that will overtop the deck. Given the fact that elevated decks tend to fail due to the large horizontal or uplift force, and not due to the downward force, the focus of this study are on the two former types of forces. The good prediction of these forces demonstrates the accuracy of the ALE solver and the validity of the truncated numerical model.

While the good prediction of the wave profiles and forces would suffice as a validation case, the accuracy of the solver was challenged further by comparing the applied pressures at selected locations. Figure 4 shows the locations of the pressure gauges that were installed on the bridge deck specimen. The comparison of the maximum pressures (filtered at $50 \mathrm{~Hz}$ ) for the four tested heights is shown in Figure 5 for four selected locations: below the overhang (P10) and the first chamber (P11), and on the offshore side of the first (P3) and second (P6) girder. This figure indicates that the numerically predicted pressures are generally matching well the experimental measurements, apart from P10 for the case SW4. For this case, the experimentally recorded pressure below the overhang is much higher than the numerical predictions, which could be probably caused by the differences in the wave shape and particularly the fact that experimentally the wave front was steeper 
than in the numerical model (due to the nonlinear shoaling). The steepness of the wave can have a major effect locally when the wave reaches the deck. Generally, the observed differences can also be attributed to differences in (i) the deck geometry, which was simplified in the numerical model, and (ii) the locations of the recorded pressures, which might differ slightly in the simulations and the experiments. Nonetheless, the reasonable agreement of the pressures for most cases provides additional evidence that the 3D slice numerical model with a bridge width of $0.25 \mathrm{~m}$ and a $0.05 \mathrm{~m}$ gap can release the trapped air from the sides of the girders in a similar way with the real bridge specimen.
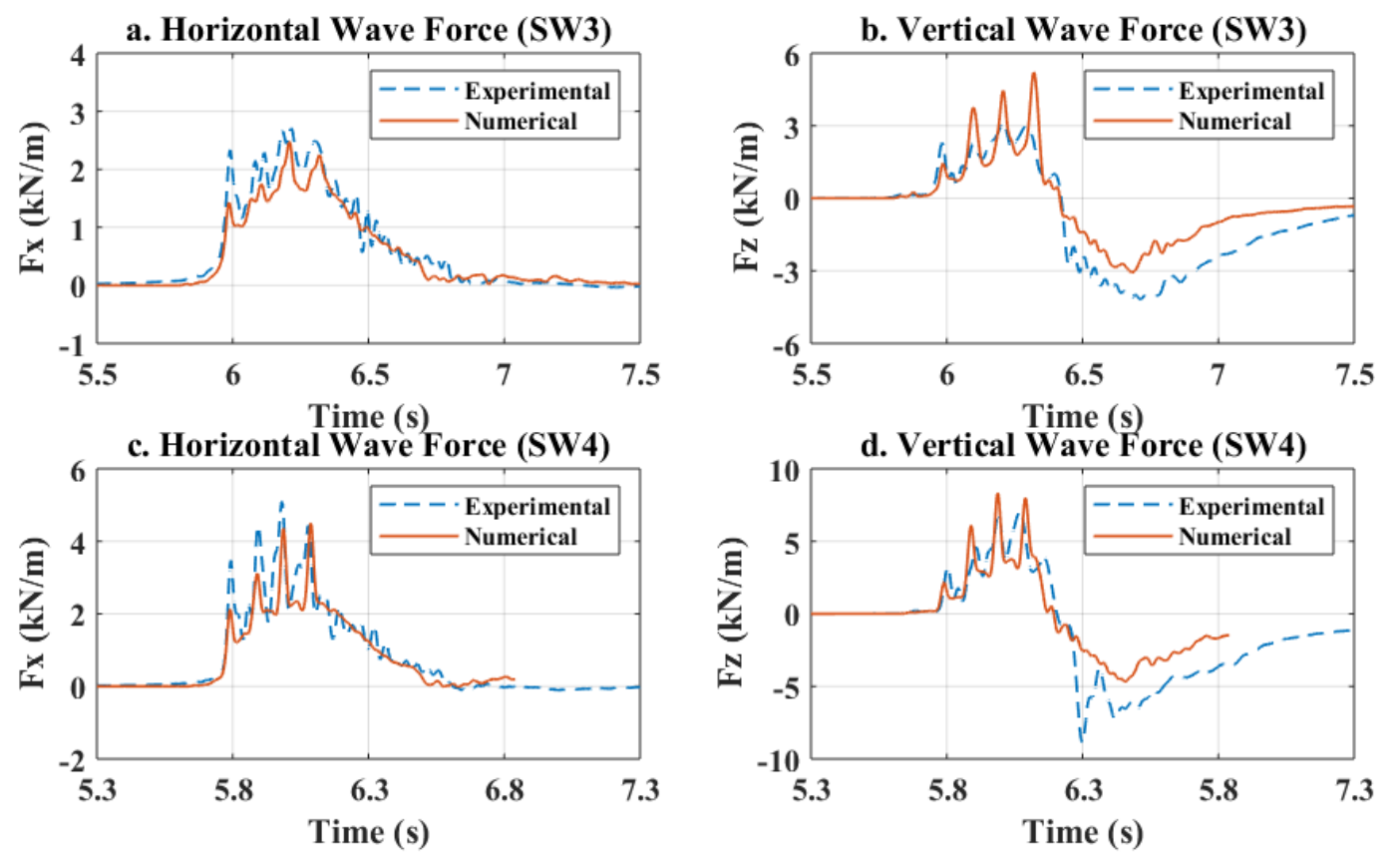

Figure 3. Comparison of wave force histories obtained from the experiments of Istrati [19] and the numerical simulations for SW3 and SW4.

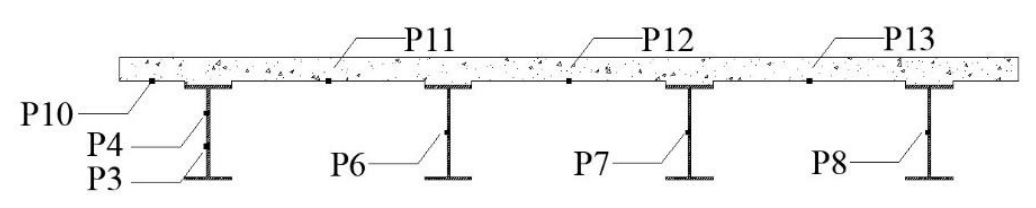

Figure 4. Locations of the pressure gauges used in the validation study

\subsection{Parametric Investigation}

For the parametric investigation of the role of the deck geometry, the numerical flume and four-girder bridge model of the validation study was used as a baseline. In addition, by keeping the deck width constant four new configurations were considered with 2, 3, 5 and 6 girders respectively, as shown in Figure 6. Furthermore, in order to expand the range of tested models, in addition to the $1.94 \mathrm{~m}$ wide baseline model, the width was increased by about $50 \%$ and $100 \%$, giving two new deck widths $(L)$ of $2.98 \mathrm{~m}$ and $4.01 \mathrm{~m}$. As shown in Figure 7, in all three models the girders and the distance between them was identical, meaning that the comparison of these configurations would give an insight into the role of the width for open-girder bridges. A summary of all the numerical models is shown in Table 1. 

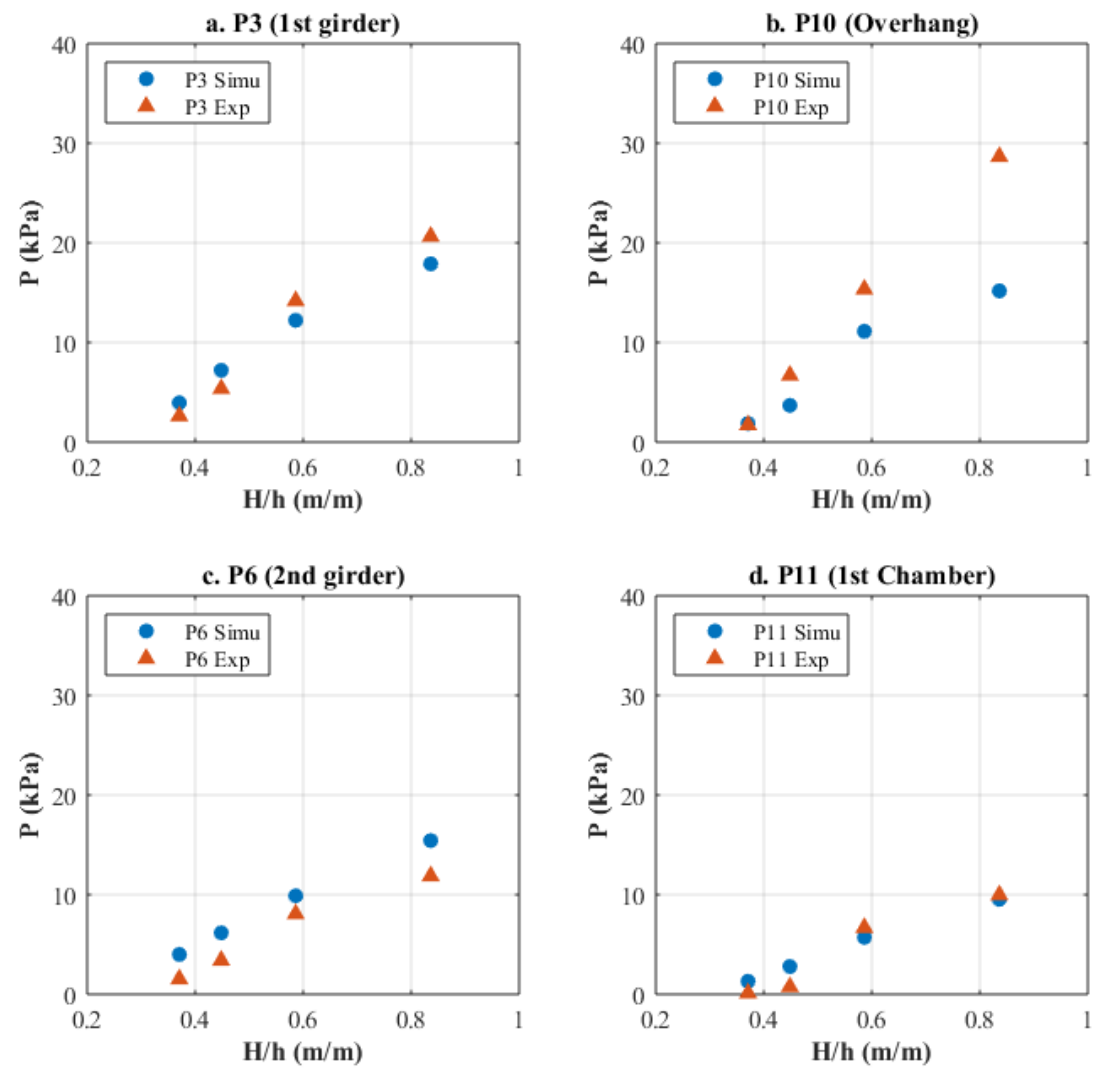

Figure 5. Comparison of maximum pressure at selected locations obtained from the experiments of Istrati [19] and the numerical simulations

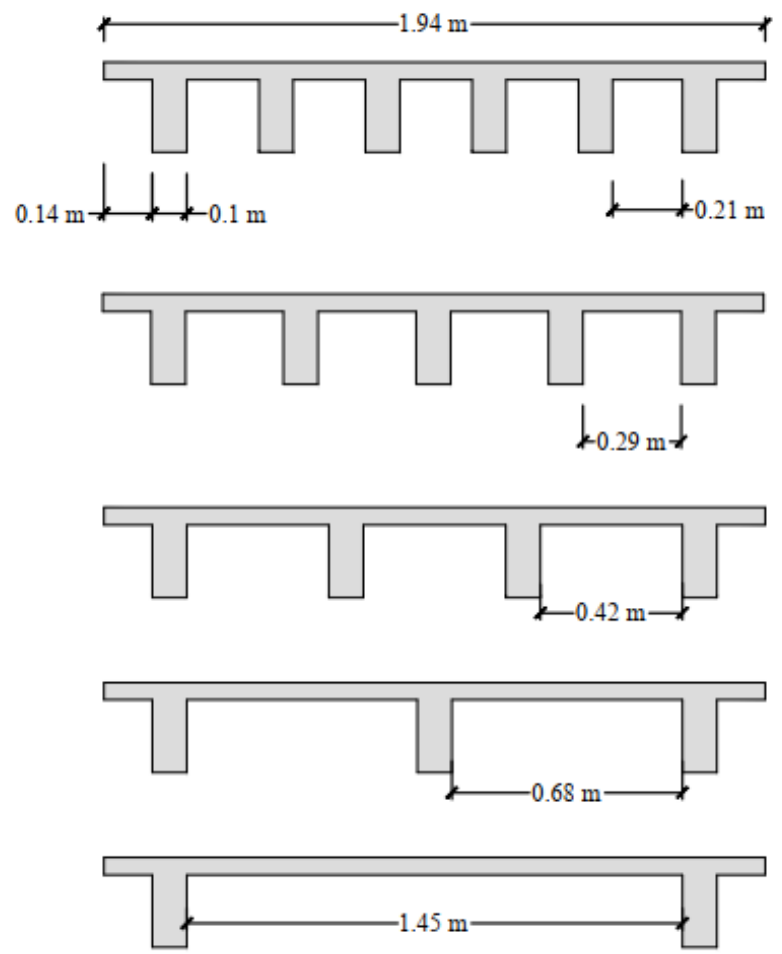

Figure 6. A schematic of the deck configurations with a different number of girders used in the present study 


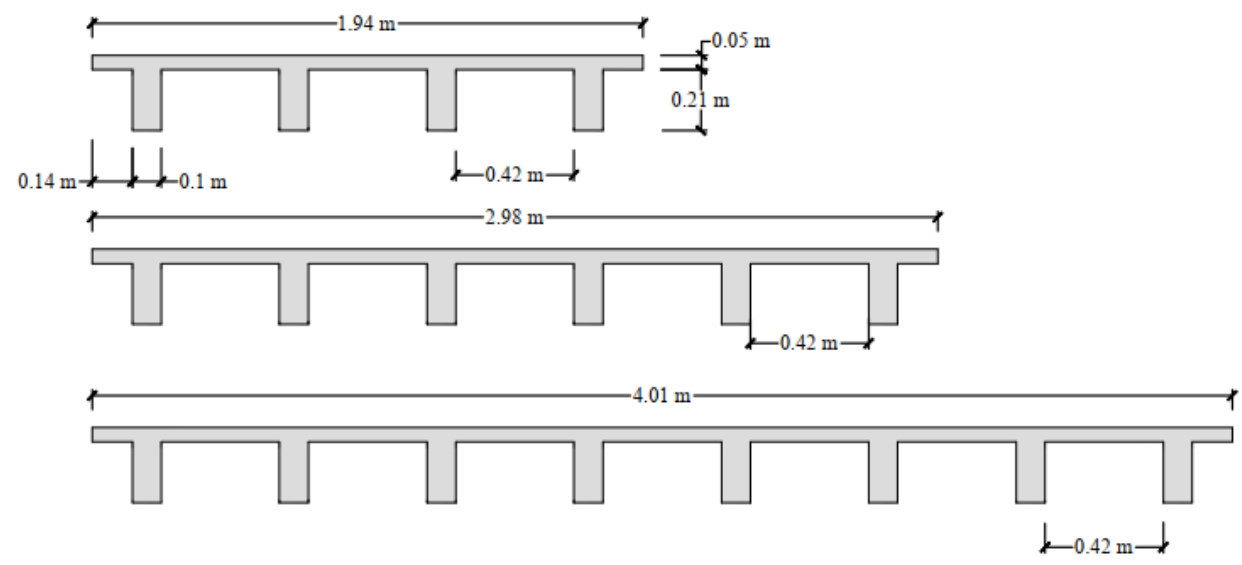

Figure 7. A schematic of the decks with a different widths used in the present study

Regarding the hydrodynamic conditions, eight wave heights are investigated numerically, including the four wave heights tested in the experiments (SW1, SW2, SW3 and SW4), and four additional wave heights (SW1.5, SW2.5, SW3.3 and SW3.6) with $\mathrm{H}=0.475 \mathrm{~m}, 0.6 \mathrm{~m}, 0.725 \mathrm{~m}$ and $0.97 \mathrm{~m}$. The still water level (h) is 1.16 meters, yielding normalized wave heights $(\mathrm{H} / \mathrm{h})$ equal to $0.37,0.41,0.45,0.52,0.59,0.63,0.73$ and 0.84 , as shown in Table 2. The mesh-size was kept the same as in the validation study, and only in the case of the wider bridges (width $2.97 \mathrm{~m}$ and $4.01 \mathrm{~m}$ ) the length of the area with the refined mesh-size, i.e. area CDEF, was extended from $3.5 \mathrm{~m}$ to $5.5 \mathrm{~m}$. All the analyses were run on the Multihaz HPC cluster of the Department of Civil and Environmental Engineering at the University of Nevada, Reno. The authors used 32 Intel Xeon E5-2650 v2 cores with $1.5 \mathrm{~TB}$ of RAM per analysis, with the run time of each being about $10 \mathrm{hrs}$.

Table 1. Summary of the bridge deck configurations

\begin{tabular}{ccc}
\hline \multicolumn{2}{c}{ Comparison A $(\boldsymbol{L}=\mathbf{1 . 9 4 m})$} & Comparison B \\
\hline Number of & Girder Spacing & Bridge Width $L$ \\
\hline 2 & 1.46 & $100 \% L,\left(L_{\text {actual }}=1.94 \mathrm{~m}\right)$ \\
3 & 0.68 & $150 \% L_{,}\left(L_{\text {actual }}=2.97 \mathrm{~m}\right)$ \\
4 & 0.42 & $\left.200 \% L_{\text {actual }}=4.01 \mathrm{~m}\right)$ \\
5 & 0.29 & \\
6 & 0.21 & \\
\hline
\end{tabular}

Table 2. Simulated wave heights

\begin{tabular}{ccc}
\hline Case \# & $\begin{array}{c}\text { Impact Wave Height } \\
\text { H (m) }\end{array}$ & $\begin{array}{c}\text { Normalized Wave } \\
\text { Height (H/h) }\end{array}$ \\
\hline SW1 & 0.430 & 0.37 \\
SW1.5 & 0.475 & 0.41 \\
SW2 & 0.520 & 0.45 \\
SW2.5 & 0.600 & 0.52 \\
SW3 & 0.680 & 0.59 \\
SW3.3 & 0.725 & 0.63 \\
SW3.6 & 0.850 & 0.73 \\
SW4 & 0.970 & 0.84 \\
\hline
\end{tabular}




\subsection{Horizontal and Vertical Forces}

Figure 8 presents the wave force histories for the five bridge decks with $N g=2,3,4,5$ and 6, for two selected wave heights. For small wave heights, e.g. SW1, both the horizontal and the uplift force increases with the increase of $\mathrm{Ng}$, with the five-girder deck witnessing 2.1 and 2.25 times larger horizontal and uplift forces respectively than the two-girder deck. However, as the wave height increases the forces on the deck with small Ng increase more than the respective forces on the large $\mathrm{Ng}$, and for SW3 the five-girder deck having to withstand about $50 \%$ and $33 \%$ of the horizontal and uplift forces respectively applied on the two-girder deck. Another distinct difference in the figures is that for small wave heights there are no short duration impulsive peaks (slamming component), however, in the wave-induced force time histories of larger heights, i.e. SW2 and SW3, it is easy to observe the slamming components on the two- and three-girder decks. In fact, it seems that the number of impulsive peaks is equal to the number of girders. These peaks become less noticeable as the girder number increases, which indicates that the impulsive component is mitigated as the girder number increases.

To determine if this true, a wavelet method was used to decompose the total force histories into the quasi-static and slamming components. An example of the decomposed components is shown in Figure 9 for SW3. The quasi-static component is a single, lowfrequency fluctuation which is caused by the interaction between the wave and the structure, while the slamming component consists of a series of high-frequency impulses caused by the wave impacts on specific girders or chambers. Interestingly, for both the horizontal and uplift direction, the number of girders has an opposite effect on the quasistatic and slamming component, with the former one being increased by the increase of $N g$, and the latter one being reduced. This opposite effect could potentially explain the complex role of $\mathrm{Ng}$ on the applied wave loads, observed in previous studies [41], [51-52].
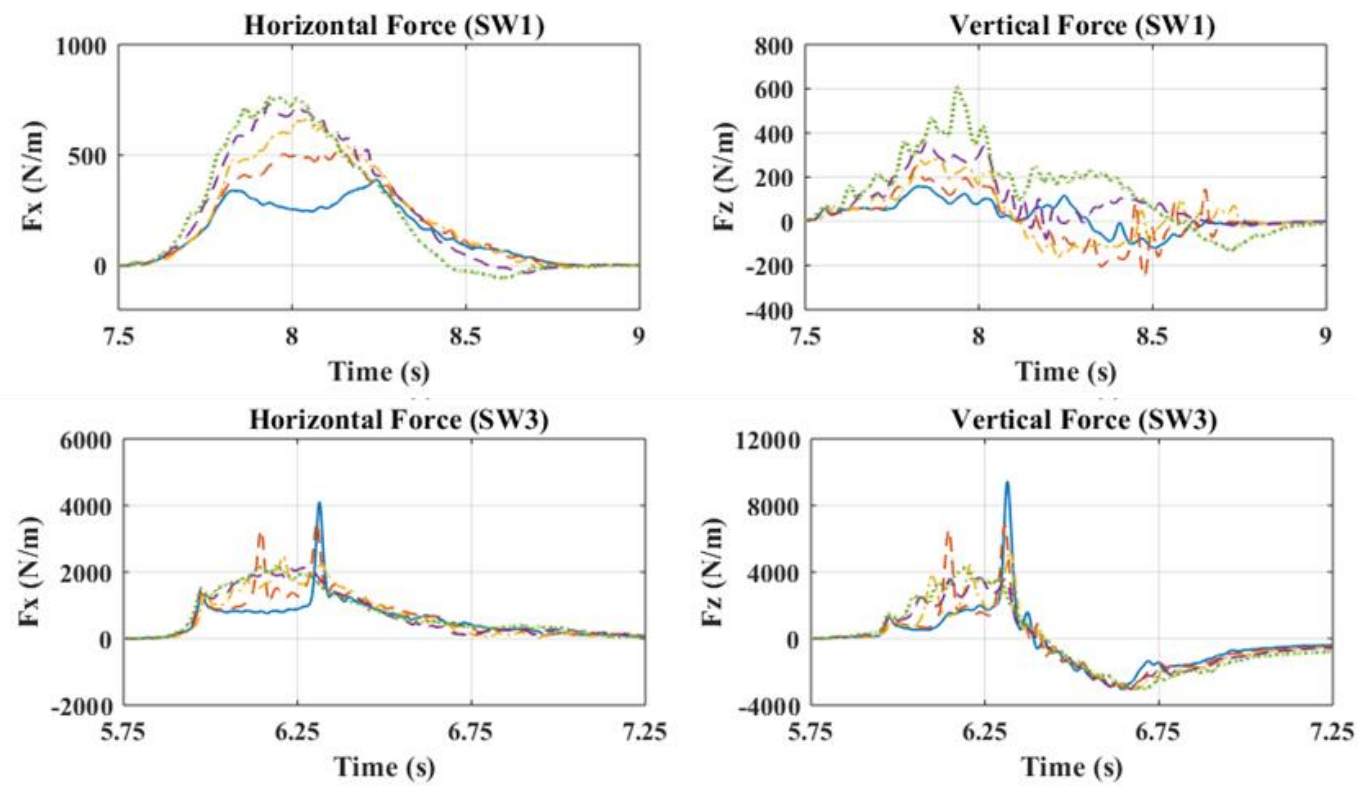

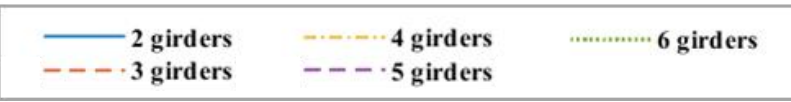

Figure 8. Time histories of wave forces on decks with a different number of girders

Figure 10 depicts the maximum values of the total horizontal and vertical wave forces, as well as the quasi-static components and slamming components, as a function of the number of girders $(\mathrm{Ng})$, for all the wave heights tested herein. As observed in the figure, there are two different trends in the total forces, one for the three small-to-intermediate wave heights SW1 SW2, where the normalized wave heights are $0.37 \sim 0.45$, and another one for the five large wave heights: SW2.5 SW4, where the normalized wave heights 
are $0.52 \sim 0.84$. For the former case, the maximum horizontal and vertical force tend to increase with $\mathrm{Ng}$ at a relatively small rate, while for the latter case the increase of the $\mathrm{Ng}$ causes major reductions of the forces at a much larger rate. Two different trends were also observed by Sarfaraz and Pak [41], who suggested that for small and intermediate wave heights $(\mathrm{H} / \mathrm{h} \leq 0.5)$, the wave forces in the vertical uplift direction tend to remain constant for different girder numbers, while for higher wave height cases, $(H / h>0.5)$, the wave forces increase as $\mathrm{Ng}$ decreases.

The explanation for the above trends is given by the decomposed components, shown in figures 10c 10f. The maximum values of the quasi-static components in the horizontal and vertical directions increase with a slow rate and in a nonlinear manner with the increase of $\mathrm{Ng}$. Compared to the total wave forces, the quasi-static component seems to have a continuously increasing rate for all the wave heights. On the other hand, the slamming component seems to be affected by $\mathrm{Ng}$ in a similar way with the total wave forces, at least for the large wave heights. For these heights, the maximum slamming forces decrease significantly with the increase of $N g$, while for small wave heights the maximum values are almost negligible, irrespective of $\mathrm{Ng}$. It is noteworthy that:

- $\quad$ For large wave heights the magnitudes of the slamming components are twice as large as the quasi-static components for the two-girder case, meaning that they will have a governing effect on the total forces. However, for the decks with the largest $N g$ (e.g. 5,6) the quasi-static components are larger than the slamming ones (due to the simultaneous reduction of $F_{s l}$ and the increase of $F_{q s}$ as $N g$ increases)

- For small wave heights the quasi-static component has a governing role over the total forces, irrespective of the number of girders.
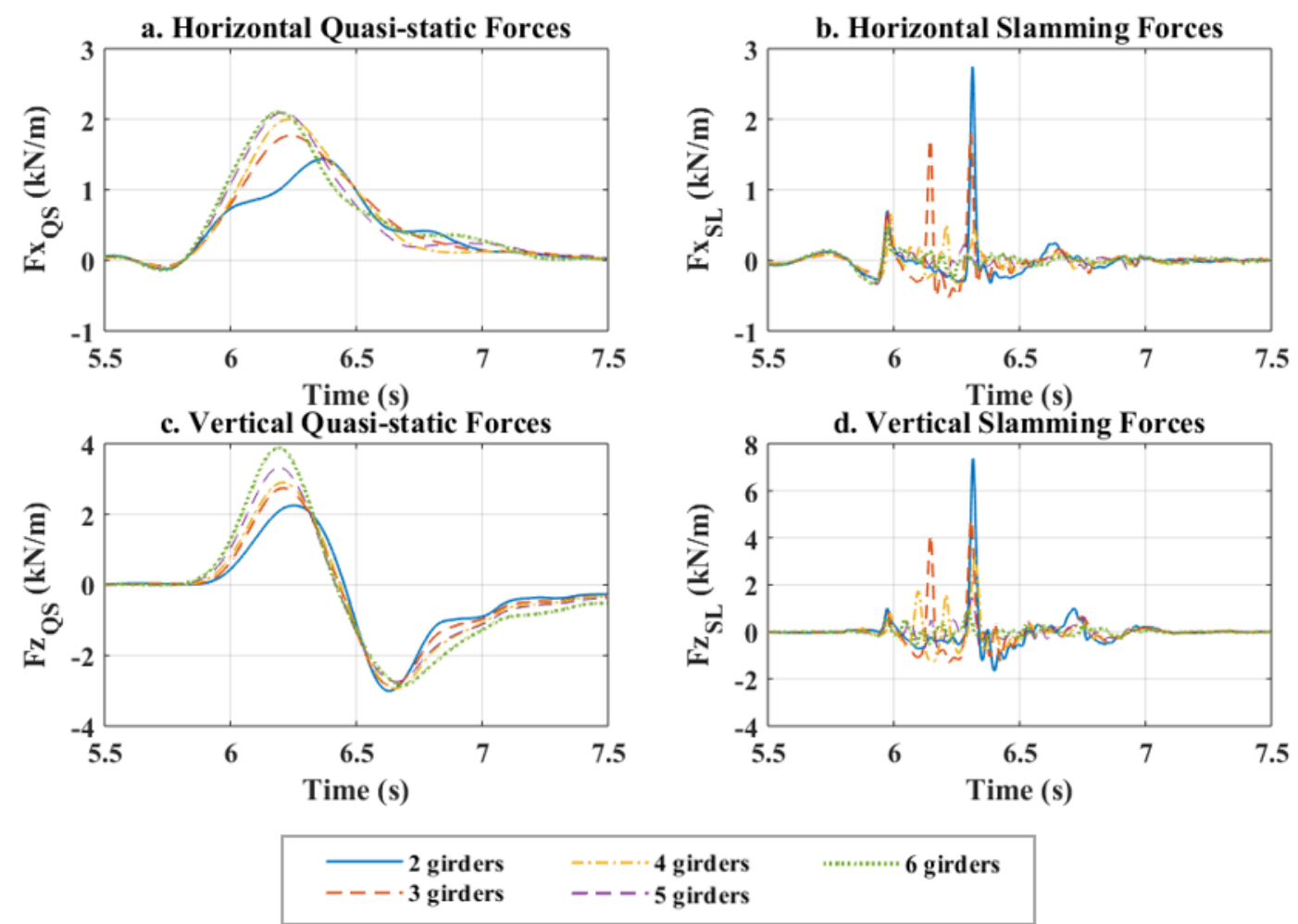

Figure 9. Time histories of quasi-static and slamming force components of decks with a different number of girders for SW3 $(\mathrm{H}=0.68 \mathrm{~m})$ 

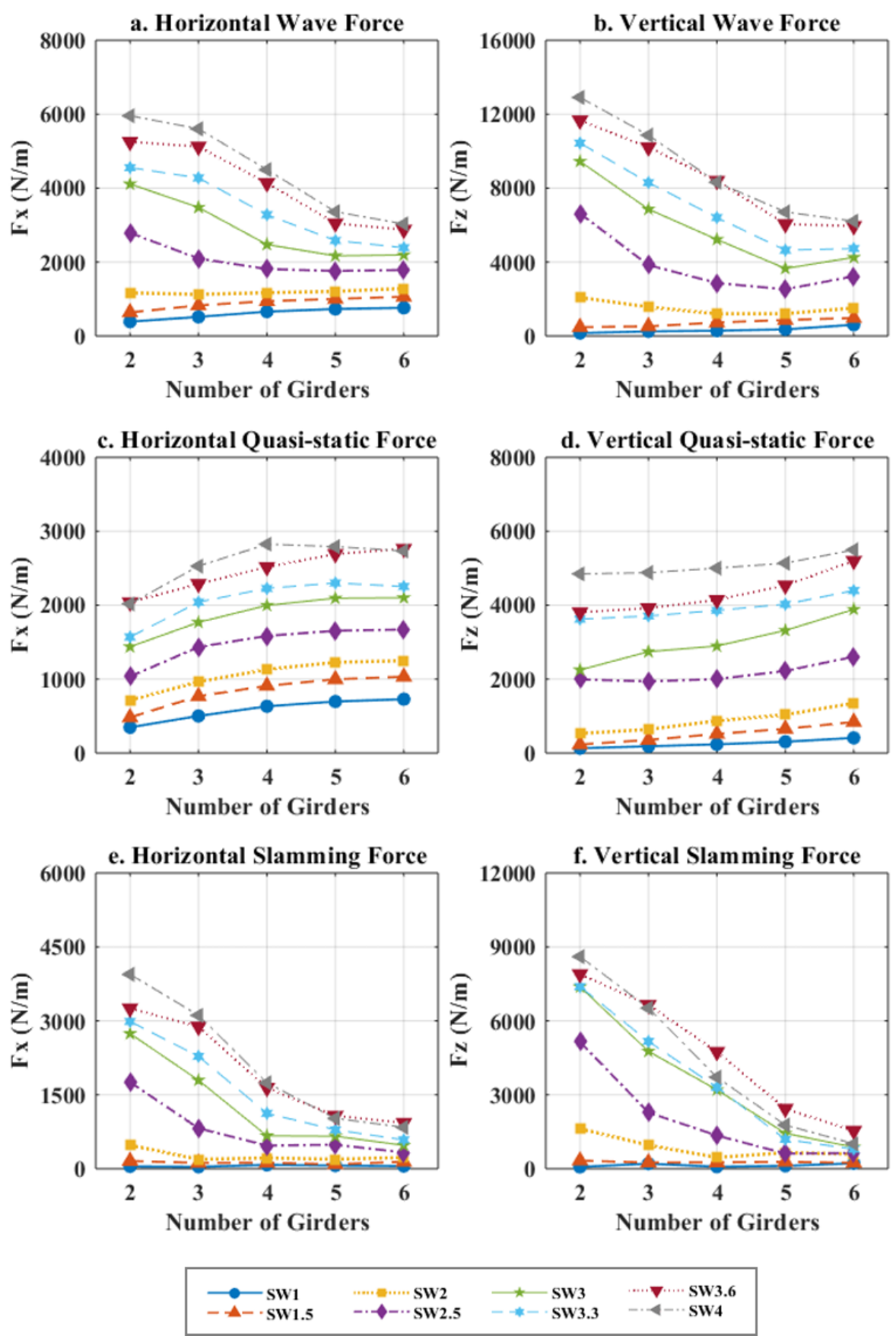

Figure 10. Maximum values of wave forces vs the number of girders in the deck

These opposite trends in the quasi-static and slamming forces provide a partial explanation of the complex trends observed in the total forces and indicate the possibility to develop predictive equations for each force component (slamming, quasi-static) separately. As discussed in Xiang et al [10], the maximum values of the two components do not occur at the same instant, complicating further the prediction of the total loads.

\subsection{Demand Diagrams}

While the investigation of the horizontal and vertical force histories gave an insight into the applied loads on a bridge, it is important to look at the temporal evolution and combination of the forces in the two directions, since they will dictate the total demand and the critical load case for the bridge. For this reason, Figure 11 shows demand diagrams (similar to the ones in Istrati et al [23]) which are the envelopes of the combination of the simultaneous horizontal and vertical forces applied during the inundation of the deck. It 
is clearly shown that the vertical wave forces are always higher than the horizontal ones (and in some cases almost twice) for different girder numbers and wave heights. Moreover, the shapes of the envelopes between the different decks with varying $N g$ have similarities, and in most cases the maximum horizontal and vertical force seem to be synchronized. The most important finding though is that the two-and three-girder bridges have the largest demand, and that this demand decrease with the increase of $\mathrm{Ng}$ up until it becomes equal to 5, above which there are no differences. This indicates that during the design of a new coastal bridge that will have to withstand the impact of extreme waves, the number of girders in the deck can be optimized in a way that the wave loads will be small enough (requires a large $N g$ ), while the volume of required construction material will not increase too much (requires a small $\mathrm{Ng}$ ).
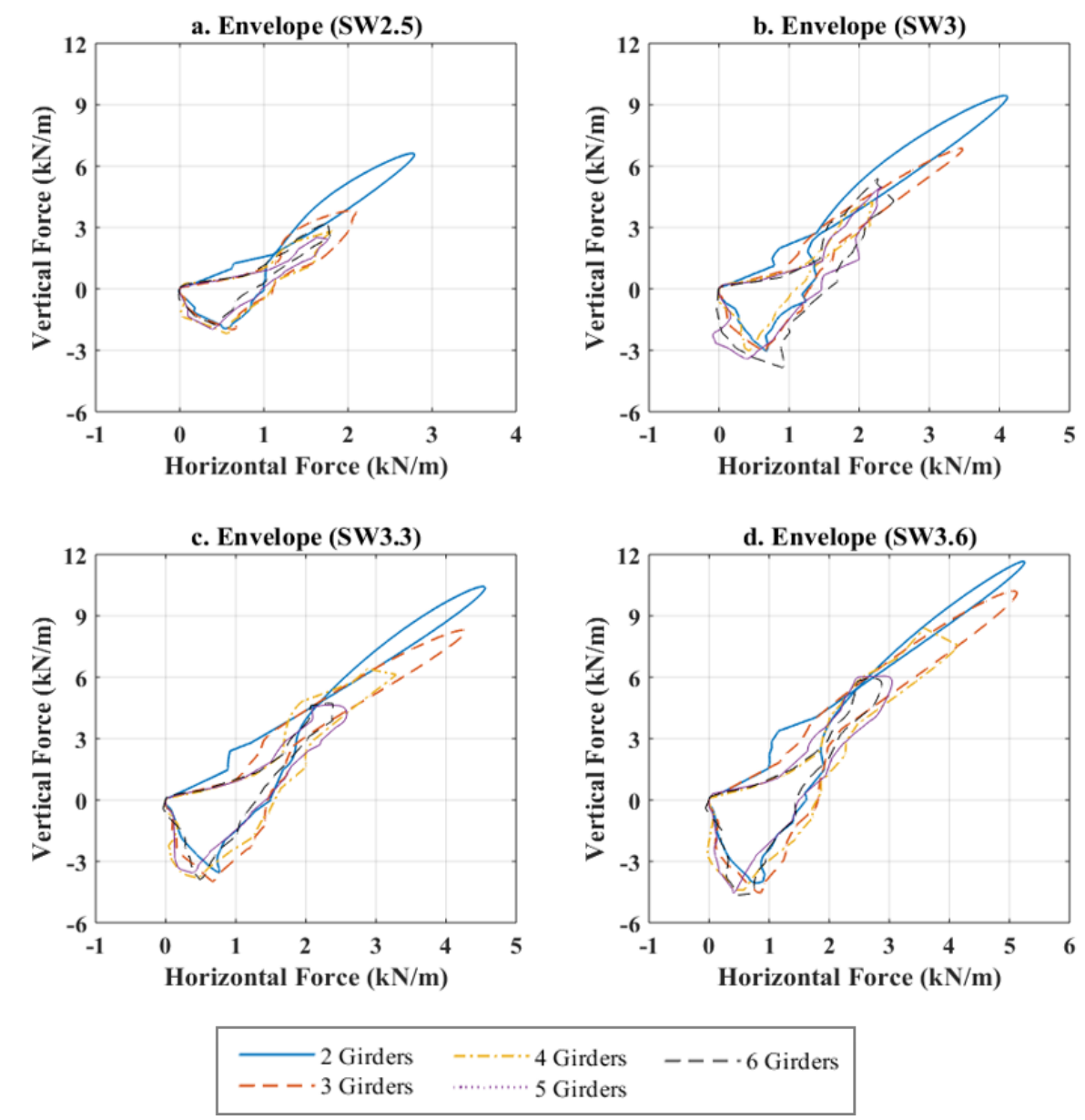

Figure 11. Envelopes of horizontal and vertical forces applied on decks with different number of girders $(\mathrm{Ng}=2,3,4,5,6)$ by four selected wave heights

\subsection{Pressures and Fluid Velocities}

Comparing the applied pressures on the two- and six-girder bridge cases can decipher the role of the number of girders and shed light on the reasons behind the observed trends. To this end the pressures were recorded numerically at different locations of the girders and below the chamber, as shown in Figure 12. On each girder, the pressure sensors are located at four elevations: the bottom of the girder, at $1 / 4,1 / 2$ and $3 / 4$ of the height, while the pressure under the deck are recorded at a $0.1 \mathrm{~m}$ interval. In Figure 13, the impact pressures applied at the mid-height of the offshore side of each girder, and at three different locations below the deck chambers, are presented for the two- and six girder deck for wave height SW3.6 (H0.85m). This figure reveals that:

- In the case of the two-girder deck the long-duration pressures on the offshore and onshore girder are quite similar, however, the onshore girder (downstream) witnesses a much larger impulsive component. Similarly, the uplift pressures below the 
deck have a major impulsive peak at the location close to the onshore side (P28), while the peak does not exist at the remaining locations below the deck.

- On the other hand, in the case of the six-girder deck the maximums of the pressure histories are much smaller, with only some small-to-negligible impulsive peaks.
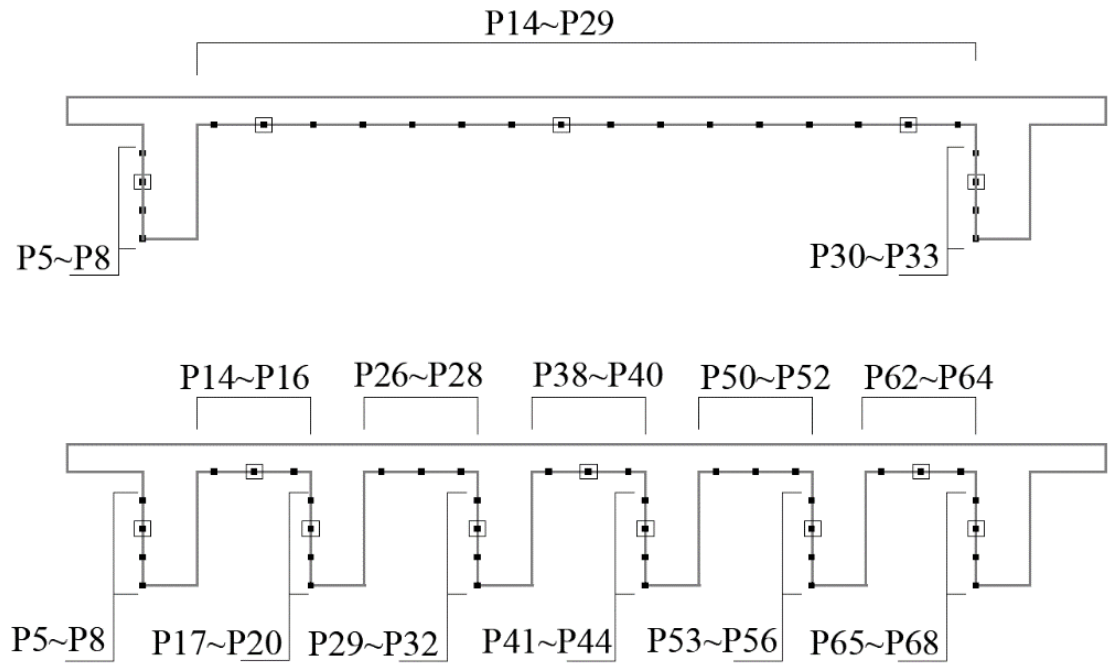

Figure 12. Locations of DBFSI pressure sensors on the girders and chambers: a. two-girder deck; b. 6-girder deck.

\section{a. Pressure on Girders (2 Girders)}

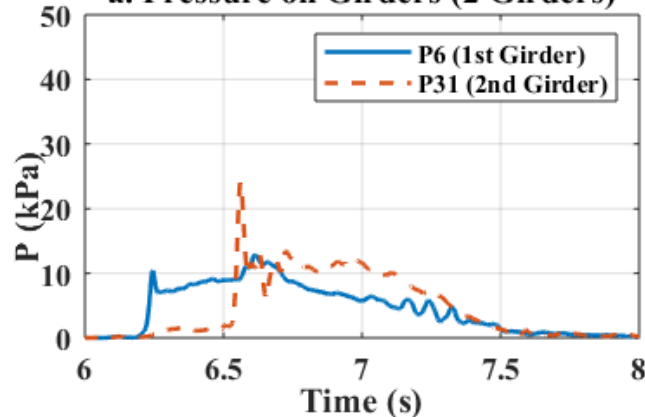

c. Pressure on Girders (6 Girders)

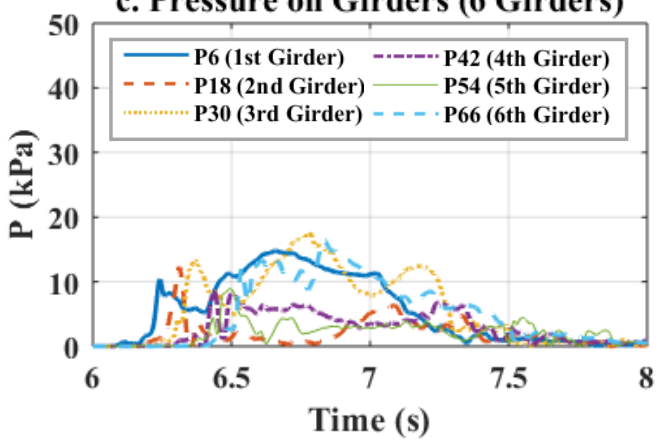

b.Pressure below Deck ( 2 Girders)
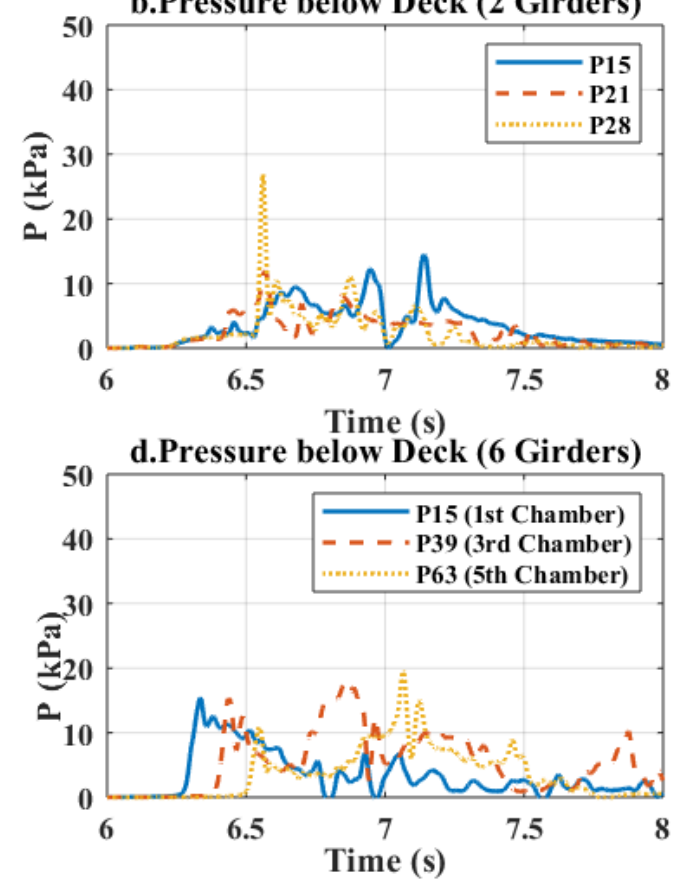

Figure 13. Pressure histories on girders (left) and below the slab (right) for the deck with two girders (top) and six girders (bottom) for wave SW3.6 (H=0.85m)

The presence of the impulsive peaks in the pressure histories has been related to the role of air in previous research studies. Takahashi et al. [55] conducted caisson model tests. One group of caisson model considered the sealed ceiling slab and the air leakage from the vertical slit wall. This situation is similar to the current study: when the wave passes through the bridge chambers during the impact, the air can escape from the side opening as the water is filling the space. Takahashi et al [55] pointed out that, when the opening rate is large, the air entrapment effect is diminished, and the waves tend to directly impact of the ceiling causing much greater forces. Cuomo et al. [56] reached similar conclusions 
and suggested that if the case of large opening ratio, the air leaks freely and the water mass impacts the deck without any resistance due to the air cushioning effect. While in the current study the air escapes from the sides and not from air-vents in the deck as in [56], the new results seem to be consistent with the findings of the aforementioned studies, since the increase of the number of girders reduces the total area of the side openings, which could potentially increase the air-cushioning effect and consequently reduce the impulsive peaks.

As demonstrated in previous sections, the increase of the bridge girders reduce the wave impact forces, which agrees partially with [41], who suggested that for certain conditions a girder can act as a barrier. This sounds surprising, given the fact the surface of the girders is the one that attracts the horizontal forces, in the first place. To provide a thorough explanation it is imperative to understand how the existence of the girders affects the wave impact process and the flow of the fluid around the deck. This can be visualized in Figures 14 and 15, which present a series of snapshots of the fluid velocity vectors in the horizontal and vertical directions respectively, for both the two- and six-girder bridge. It can be observed that:

- In the two-girder case, the wave impacts first the upstream (offshore) girder, then it reaches the bottom of the deck -at a location close to the mid-width- and after that it accelerates and impacts the downstream girder and deck slab with much larger horizontal and vertical velocities. These large velocities are the reason for the generation of the impulsive pressures and slamming component of the total horizontal and uplift forces.

- On the other hand, in the case of the six-girder bridge, the wave does not accelerate and the horizontal velocities remain low when the wave reaches the downstream girder. However, in the vertical direction, although the wave accelerates and impacts the last chamber next to the downstream girder with a large velocity, this impact happens on a small area, while at the same instant the velocities in the remaining chambers are in the negative direction (pointing downwards), meaning that those chambers do not contribute significantly to the total uplift. In contrast, at the same instant in the two-girder case the wave impacts violently on a larger area close to the downstream side of the deck (since it is not limited by the presence of additional girders) while the majority of the remaining area below the deck is witnessing pure buoyancy, resulting in larger total uplift forces than the six-girder deck.

In summary, in addition to the air escape from the sides of the deck, the main reason for the generation of larger horizontal forces on the bridges with two and three girders, is the acceleration of the fluid particles after the initial impact on the offshore girder, and the existence of a long chamber that allows the fluid to increase its velocity. For a large number of girders, the flow is blocked by each girder forming unsynchronized eddies in each chamber, and the wave impact is broken into multiple smaller and weaker impacts, mitigating the overall wave effect. 
a.

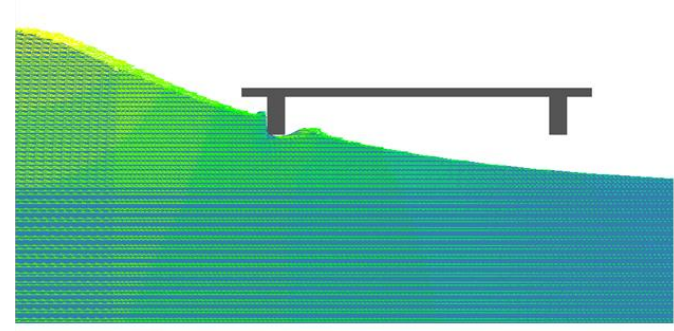

b.

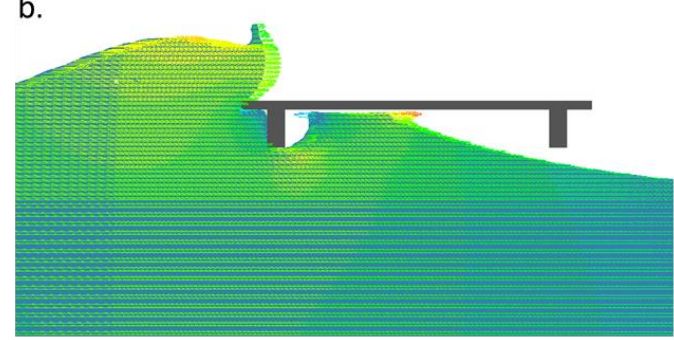

c.

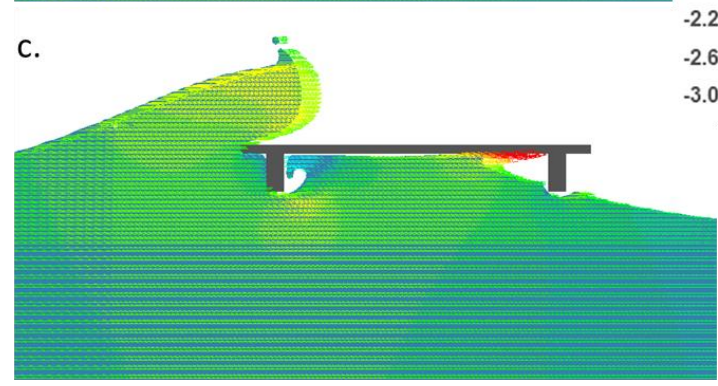

Vectors of X-velocity

$5.000 \mathrm{e}+00$
$4.600 \mathrm{e}+00$
$4.200 \mathrm{e}+00$
$3.800 \mathrm{e}+00$
$3.400 \mathrm{e}+00$
$3.000 \mathrm{e}+00$
$2.600 \mathrm{e}+00$
$2.200 \mathrm{e}+00$
$1.800 \mathrm{e}+00$
$1.400 \mathrm{e}+00$
$1.000 \mathrm{e}+00$
$6.000 \mathrm{e}-01$
$2.000 \mathrm{e}-01$
$-2.000 \mathrm{e}-01$
$-6.000 \mathrm{e}-01$
$-1.000 \mathrm{e}+00$
$-1.400 \mathrm{e}+00$
$-1.800 \mathrm{e}+00$
$-2.200 \mathrm{e}+00$
$-2.600 \mathrm{e}+00$
$-3.000 \mathrm{e}+00]$
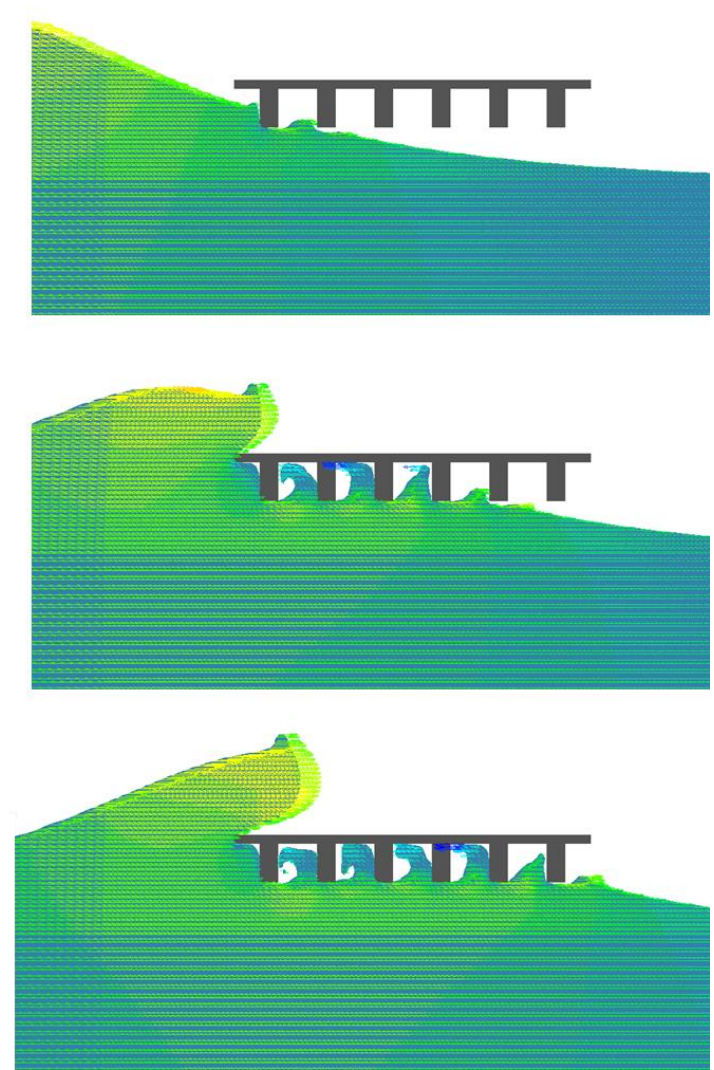

Figure 14. Snapshots of the vectors of the horizontal fluid velocities of wave SW3.6 $(\mathrm{H}=0.85 \mathrm{~m})$ impacting a deck with two girders (left) and six girders (right) at three instants: (a) $t=6.2 \mathrm{~s}$, (b) $t=6.4 \mathrm{~s}$ and (c) $t=6.5 \mathrm{~s}$

a.
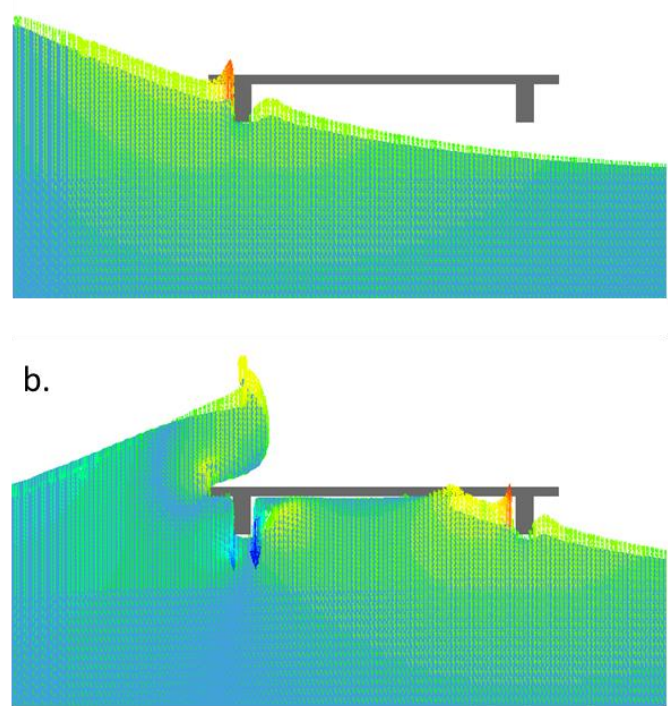

Vectors of Z-velocity

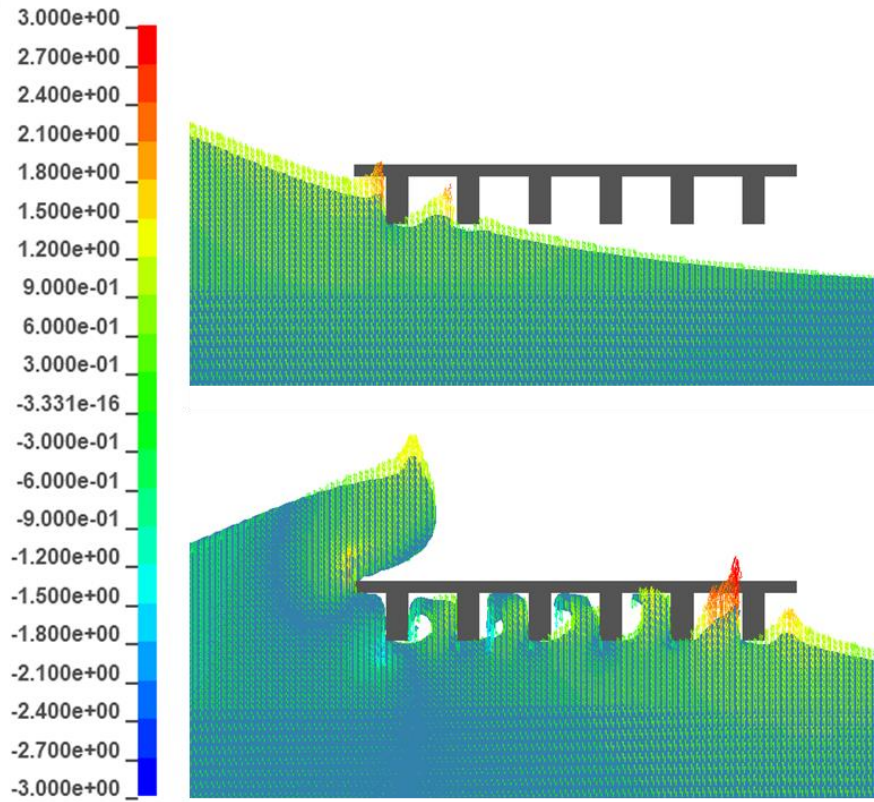

Figure 15. Snapshots of the vectors of the vertical fluid velocities of wave SW3.6 $(\mathrm{H}=0.85 \mathrm{~m})$ impacting a deck with two girders (left) and six girders (right) at two instants: (a) $\mathrm{t}=6.2 \mathrm{~s}$ and (b) $\mathrm{t}=6.5 \mathrm{~s}$ 


\subsection{Horizontal and Vertical Forces}

This section will focus on the effect of the bridge width on the wave loads by comparing three bridge widths: $100 \%, 150 \%$ and $200 \%$ of the width $L$ of the baseline model. The spacing between the girders remains constant for the three different bridge widths, which means that the decks will have 4, 6 and 8 girders respectively. Figure 16 shows the time histories of the horizontal and vertical forces for two large wave heights (SW3 and SW4). These histories exhibit clear differences, with the wider bridges having additional impulsive peaks both in the horizontal and upward direction. In fact, the number of the impulsive peaks correlates to the number of the girders. Moreover, it is noticed that the increase of the bridge width tends to elongate the impact duration and consequently the duration of the applied horizontal and uplift force. Surprisingly though, the differences in the magnitudes of the maximum forces are minor-to-negligible. The reason for that is related to the fact that the maximum forces seem to occur when the wave reaches the 4 th girder, thus, the additional girders in the wider bridge decks do not contribute much to the total forces.

The observed trend in the time histories of the previous figure, is consistent for all the wave heights, as shown by the maximum total forces in Figure 17. Only for the large wave heights with $(H / h)>0.5$ the horizontal forces seem to increase slightly with the width, and the two longer widths $(150 \% L$ and $200 \% L)$ give similar results. Generally, looking at the decomposed components it can be concluded that the slamming force component is the one that is affected more by the bridge width, which in turn increases slightly the horizontal forces (less than $10 \%$ ) but has a negligible effect on the maximum uplift forces. This is an important finding, because it seems to contradict many of the available force predictive equations that are a function of the bridge deck. Moreover, the minor-to-negligible effect of the deck width on the maximum forces observed in the current study, seems to differ from the significant increase of the uplift force for larger widths observed by Hayatdavoodi et al. [57]. This could probably be attributed to the fact that the aforementioned researchers focused on submerged plates and periodic waves. For an elevated bridge deck with girders, the process of the wave impact is more complicated.
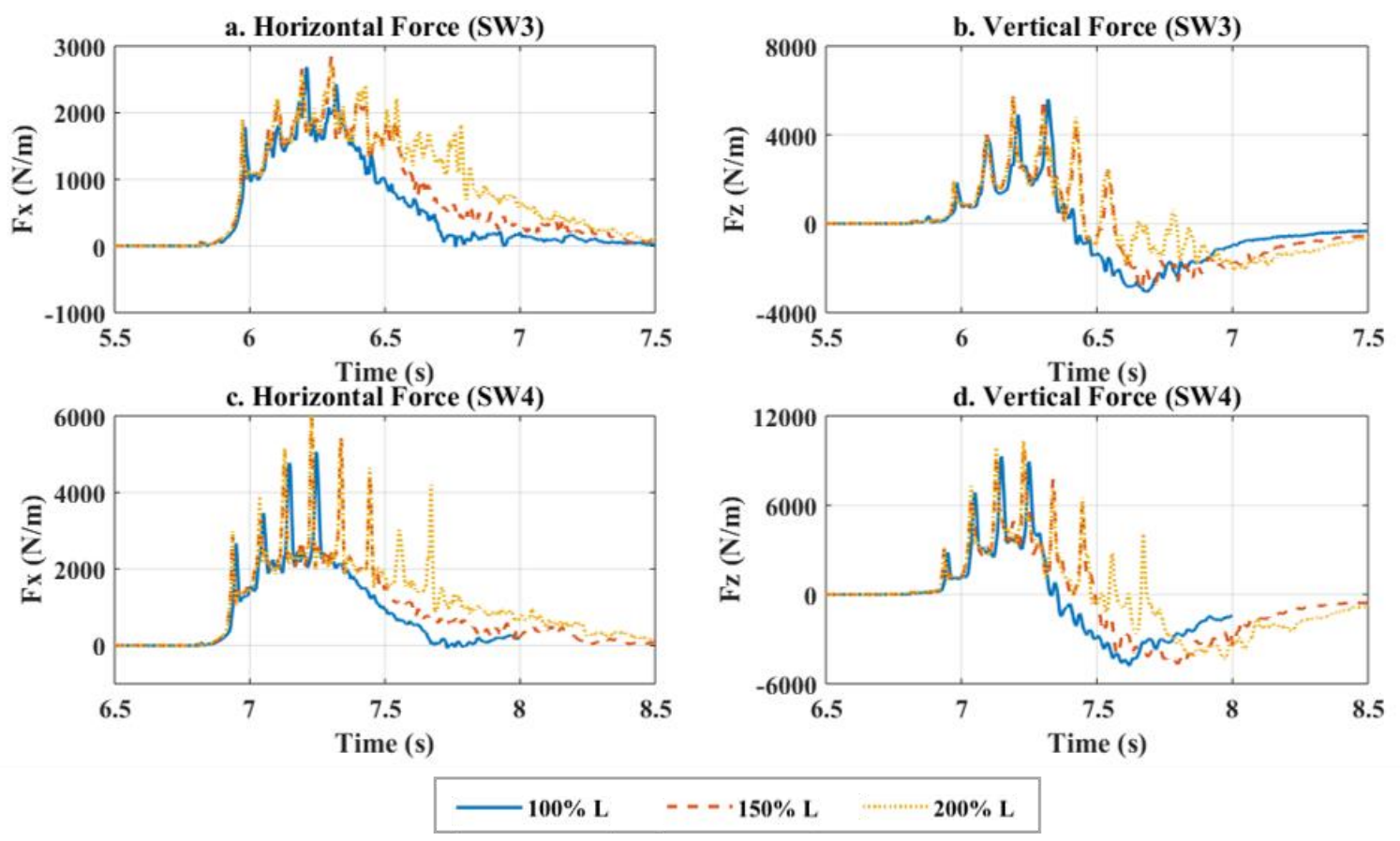

Figure 16. Wave force histories applied on three bridge decks with different widths 

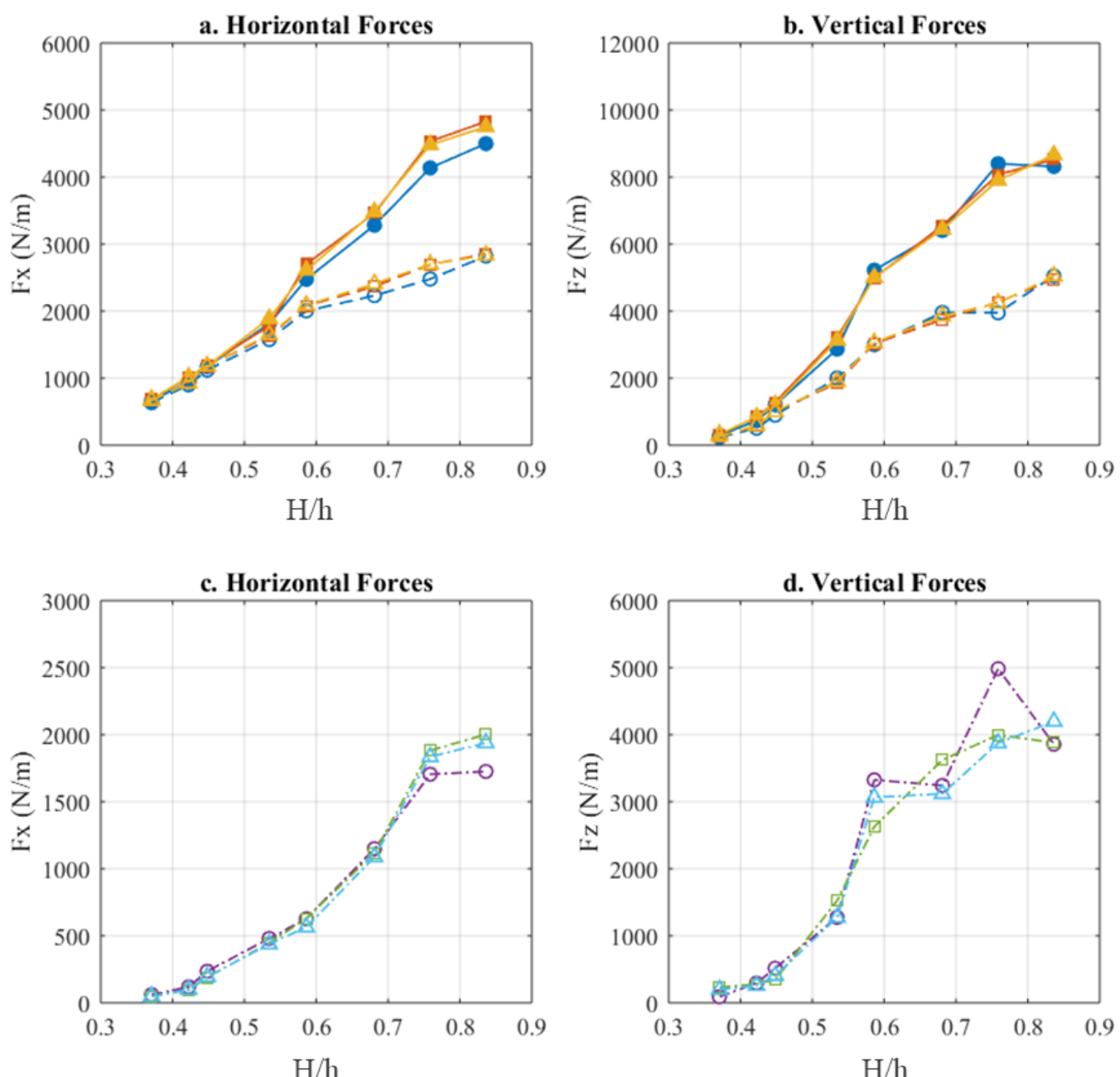

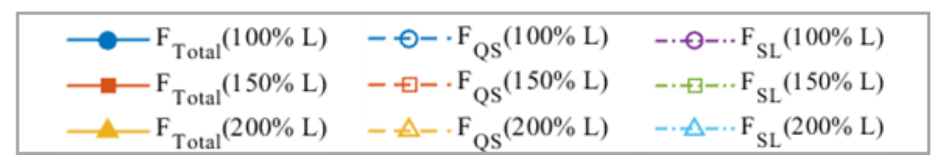

Figure 17. Comparisons of numerically predicted maximum wave forces (total, slamming and quasi-static) for different bridge deck widths

\subsection{Wave Impact Process}

Figure 18 presents a series of snapshots of the wave impact process on one of the wider decks $(150 \% L)$ and the associated fluid velocity vectors in the vertical direction, which will help explain the negligible effect of the deck width. The entire inundation process can be divided into three main steps. The first step takes place when the wave contacts the deck. Since the deck is elevated from the still water level, the wave usually reaches first the bottom of the upstream girder. After hitting the upstream girder, the water level will reach the overhang generating a first peak in the uplift force histories. In the second step, the wave will keep propagating through the deck, which increases the water level in the chambers forming locally air-pockets until they escape from the sides and the whole chamber becomes inundated. The sequential inundation of the chambers in step 2, will keep increasing the total forces, until the wave crest starts overtopping the deck, which will initiate the last step. The downward pressures applied by the water above the deck, counteracts the applied uplift pressures in the chambers resulting ultimately in smaller total forces. Interestingly, these snapshots reveal that the overtopping occurs for the first time slightly after the impulsive upward impact on the 3rd chamber, or in other words when the wave has inundated the four girders (less than $100 \% L$ ). This explains why the wider bridges with $150 \% L$ and $200 \% L$ see similar forces with the baseline model with 
$100 \% L$, since by the time the wave reaches the remaining chambers the crest of the wave has already overtopped the deck. Moreover, while the $200 \% \mathrm{~L}$ is not shown in this figure, it must be noted that for very wide decks the solitary wave cannot inundate the whole width, since the maximum inundation will be limited by the wavelength. By the time the wave reaches the downstream girder, the wave has already passed the upstream girder and overhang, meaning that it applies pressures only on a part of the deck width.

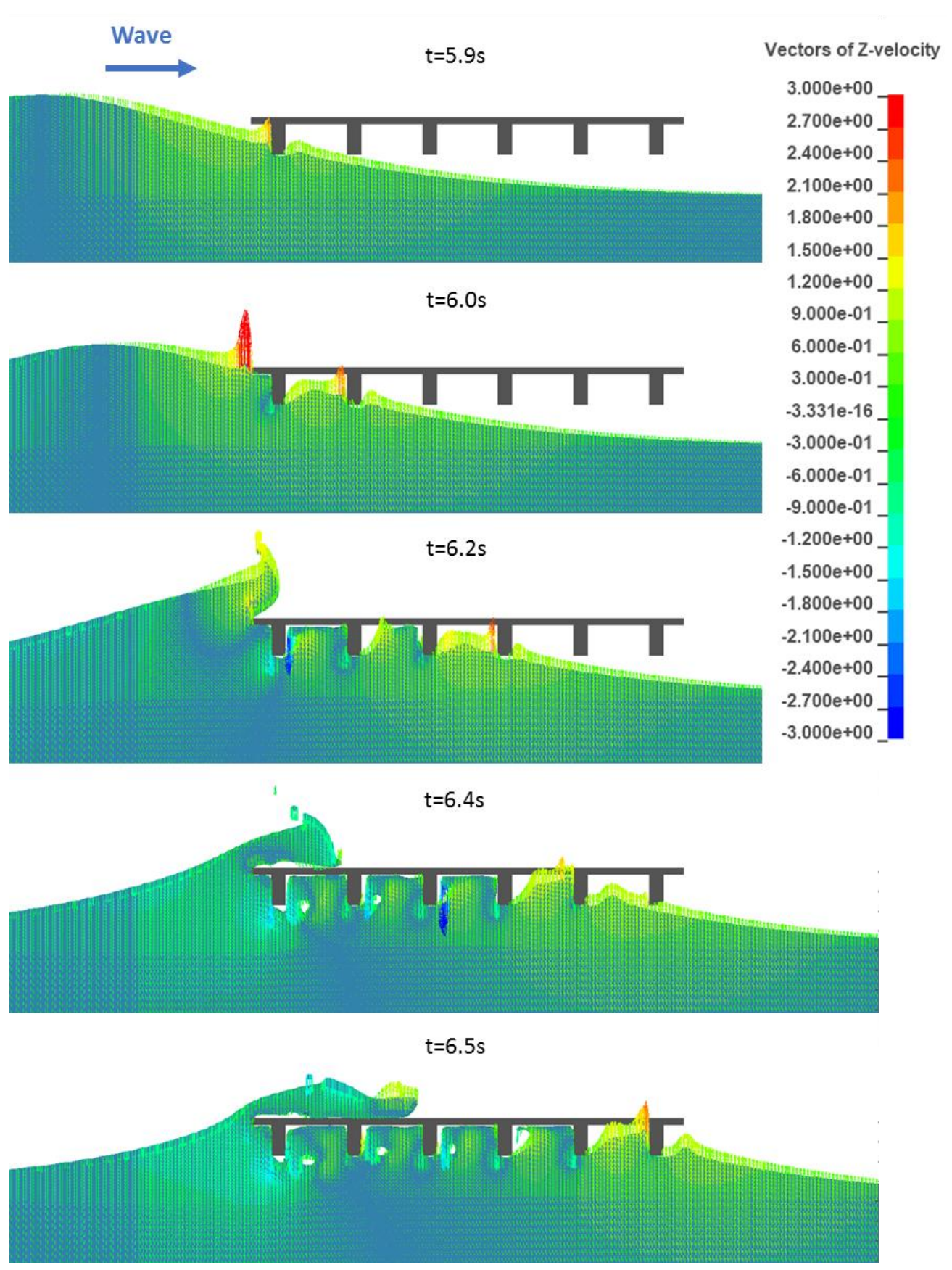

Figure 18. Vectors of $z$-velocity during the impact of wave $S W 3(\mathrm{H}=0.68 \mathrm{~m})$ on the deck with $150 \%$ L 


\subsection{Motivation}

As discussed in the introduction the role of the number of girders has not yet been deciphered. Thus, there are simplified predictive equations of wave loads in the literature, which give larger forces for a larger number of girders $\mathrm{Ng}$ (e.g. [7], [8]) or are independent of the $\mathrm{Ng}$ (e.g. [9]). Based on the findings of the previous section, it became clear that (i) the number of girders $\mathrm{Ng}$ has a different effect on the slamming and quasi-static forces, and (ii) the bridge width does not affect significantly the maximum forces on an elevated deck. These findings can help improve existing wave force prediction methods. For example, Azadbakht and Yim [9], who investigated numerically five coastal bridges inundated by tsunami waves, developed the following prediction equations for the horizontal and vertical wave force:

Horizontal force:

Vertical force:

$$
F_{H_{-} A Y}=0.5 \rho g\left(2 \times h_{0}-L_{h}\right) L_{h}+0.5 C_{d} \rho v^{2} L_{h}
$$

$$
F_{V_{-} A Y}=C_{U P}\left[\rho g V+0.5 C_{l} \rho v^{2} L\right]
$$

where $L_{h}$ is the height of the bridge superstructure, $h_{0}$ is the difference between the bottom of the deck and the maximum free-surface.

In equation (9), the vertical wave force is related to the parameters $V$ and $L$, which are the full deck volume and its width. Therefore, this prediction method may not be very accurate for the elevated decks investigated in the current study, which are not fully inundated by the waves. In figure 19, the force estimated by equations (8) and (9) are compared with the simulation results for the three bridge widths presented in the previous section. In the horizontal direction, figure 19a shows that the predicted wave forces follow similar trends with the numerical results, although, their magnitudes are smaller for all the wave heights. On the other hand, the predicted vertical wave forces shown in figure $19 \mathrm{~b}$, increase significantly with the bridge width, which contradicts the numerical simulations.
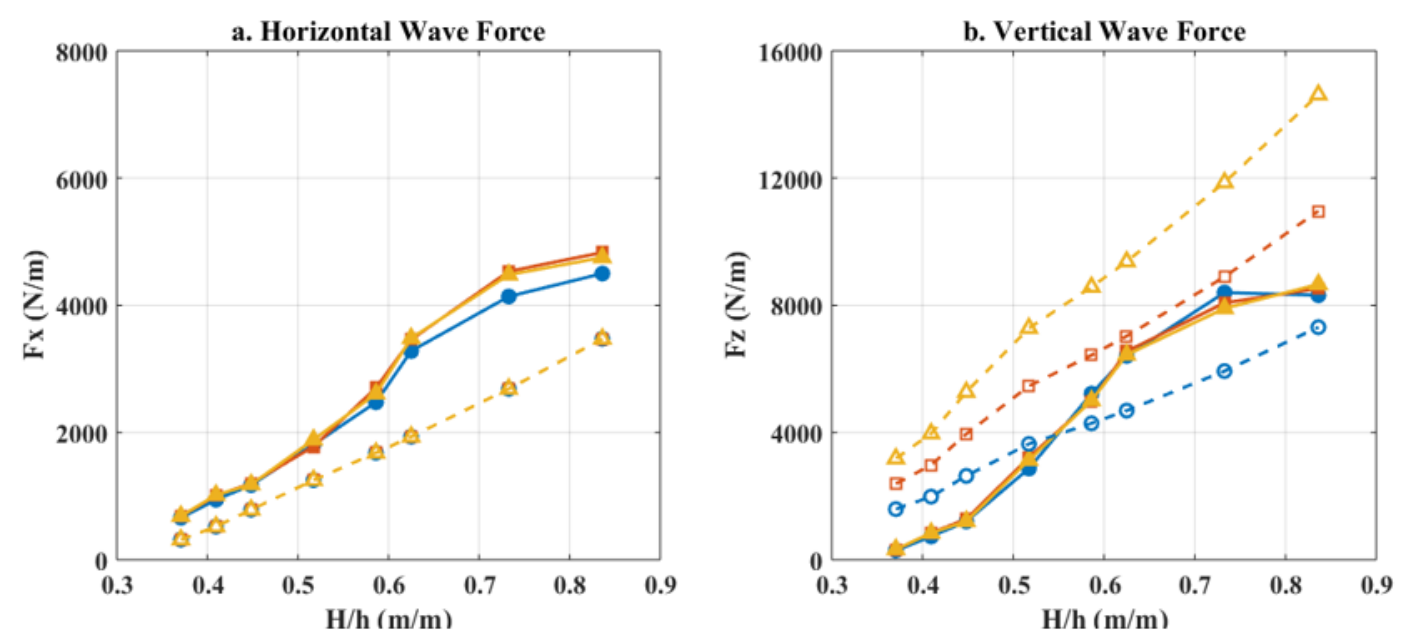

\begin{tabular}{|l|l|}
\hline- Numerical $100 \%$ L & $-\oslash-\cdot$ Predicted $100 \%$ L \\
-- Numerical $150 \%$ L & $-\succeq-\cdot$ Predicted $150 \%$ L \\
-- Numerical $200 \%$ L & $-\triangle-$ Predicted $200 \%$ L \\
\hline- N
\end{tabular}

Figure 19. Maximum wave forces vs the normalized wave height for different bridge widths, obtained from numerical simulations and predicted by the simplified equations of Azadbakht and Yim [9]

\subsection{Formulation}

In a more recent study [10], the simplified methodology of [9] was used as a reference $\left(F_{H_{-} A Y}, F_{V_{-}} A Y\right)$ and was updated in order to account for the effect of the bridge elevation $\mathrm{Z}$ 
on the quasi-static and slamming components. This approach yielded more accurate predictive equations for the forces (eq. (10), (11)) by utilizing non-dimensional coefficients for each force component (eq. (12), (13), (14), (13)), as shown below:

Horizontal:

Vertical:

$$
F_{H_{-} X i}=F_{H_{-} A Y} *\left(C_{H_{q S}}+C_{H_{S l}}\right) \text {; }
$$

$$
F_{V_{-} X i}=F_{V_{-} A Y} *\left(C_{V_{q s}}+C_{V_{s l}}\right)
$$

Where the four coefficients $C$ are the quasi-static and slamming coefficients and are correlated to the bridge elevation $Z$, the wave height $H$, and the bridge width $L$ in the horizontal and vertical directions.

Horizontal direction:

$$
\begin{gathered}
C_{H_{q S}}=0.43 e^{0.89(\sqrt{Z L} / H)} \text { for } 0<\frac{\sqrt{Z L}}{H}<1.8 \sqrt{L} ; \\
C_{H_{S l}}=2.5(\sqrt{H L} / Z)^{-0.9} \text { for } 0.72 \sqrt{L}<\frac{\sqrt{H L}}{Z}<25.1 \sqrt{L} ;
\end{gathered}
$$

Vertical (upwards) direction:

$$
\begin{gathered}
C_{V_{q s}}=\left[24(\sqrt{H L} / Z)^{-2.2}+0.9\right]^{-1} \text { for } 0.72 \sqrt{L}<\frac{\sqrt{H L}}{Z}<25.1 \sqrt{L} ; \\
C_{V_{s l}}=\left[20(\sqrt{H L} / Z)^{-2}+1\right]^{-1} \text { for } 0.72 \sqrt{L}<\frac{\sqrt{H L}}{Z}<25.1 \sqrt{L}
\end{gathered}
$$

Based on the numerical results, the number of girders tends to have a strong influence on the wave forces applied on the deck, while the deck width is less influential. In fact, for a constant bridge width increasing the $\mathrm{Ng}$ will reduce significantly the total and the slamming forces in both directions, while the effect on the quasi-static forces is much less. Therefore, for the purpose of developing improved simplified equations, one could neglect the effect of $\mathrm{Ng}$ on the quasi-static forces and keep the ones from Xiang et al [10], i.e. eq. (12) and (14), but developed improved coefficients for the slamming coefficients that will be a function of $\mathrm{Ng}$.

Moreover, since the numerical results revealed that the bridge width has a small-tonegligible effect on the total forces, it must be ensured that the updated slamming coefficients, will be a function of the number of girders $\mathrm{Ng}$, but will not increase with the deck width. Therefore, it makes sense to relate the slamming forces to the chamber width (distance between consecutive girders), which remains constant for a wider bridge with the same spacing of girders, as the maximum forces do. The chamber spacing can be represented as $L / N g$ which incorporates both the deck width $L$ and the girder number $N g$. Furthermore, since the predictive equation for the uplift force developed by the aforementioned study [9] increase with the increase of the bridge width, which contradicts the numerical results, the new reference force for the estimation of the slamming component will be modified by the factor $L_{\text {wave }} / L$. In this case, $L_{\text {wave }}$ is the characteristic wavelength of a solitary wave, which is defined by Goring [58] as:

$$
L_{\text {wave }}=1.5 \sqrt{h^{3} / H}
$$

Where $h$ is the still water level, and $H$ is the wave height. Using the above factor, the uplift force $\left(F_{V_{-}} A Y\right)$ will be modified as shown in eq. (17), making the new reference uplift force a function of the Lwave instead of the deck width.:

$$
F_{V r e f}=F_{V_{-} A Y} * \frac{L_{\text {wave }}}{L}
$$


Taking all the above tends into account, it was decided to relate the new slamming coefficients to a new unitless parameter $\sqrt{\mathrm{H} \frac{\mathrm{L}}{\mathrm{Ng}}} / Z$, in order to incorporate the influence of the deck geometry. Figure 20 plots the normalized ratios of the slamming force components, i.e. the maximum slamming components of the forces predicted by the simulations divided by the corresponding reference forces, as function of the new unitless parameter for each case. Note that in this figure the reference force in the horizontal direction is given by eq. (8) and in the vertical direction by eq. (17). Given the reasonable correlation of the slamming coefficients with the new parameter shown in in Fig. 20, a linear regression line is used to describe their relationship. Therefore, the new slamming coefficients are given as:

Horizontal:

Vertical:

$$
C_{H 2_{s l}}=0.0723(\sqrt{H L / N g} / Z)^{2.5}
$$

$$
C_{V 2_{s l}}=0.0127(\sqrt{H L / N g} / Z)^{4.34}
$$

The updated wave force prediction equations become:

Horizontal:

Vertical:

$$
F_{H}=F_{H_{-} A Y} *\left(C_{H_{q S}}+C_{H 2_{s l}}\right)
$$

$$
F_{V}=F_{V_{-} A Y} *\left(C_{V_{q s}}+C_{V 2_{s l}} * \frac{L_{w a v e}}{L}\right)
$$

Where $F_{H \_} A Y$ and $F_{V_{-}} A Y$ are given by eq. (8) and (9) respectively, the quasi-static coefficients by eq. (12) and (14), and the slamming coefficients by eq. (18) and (19).
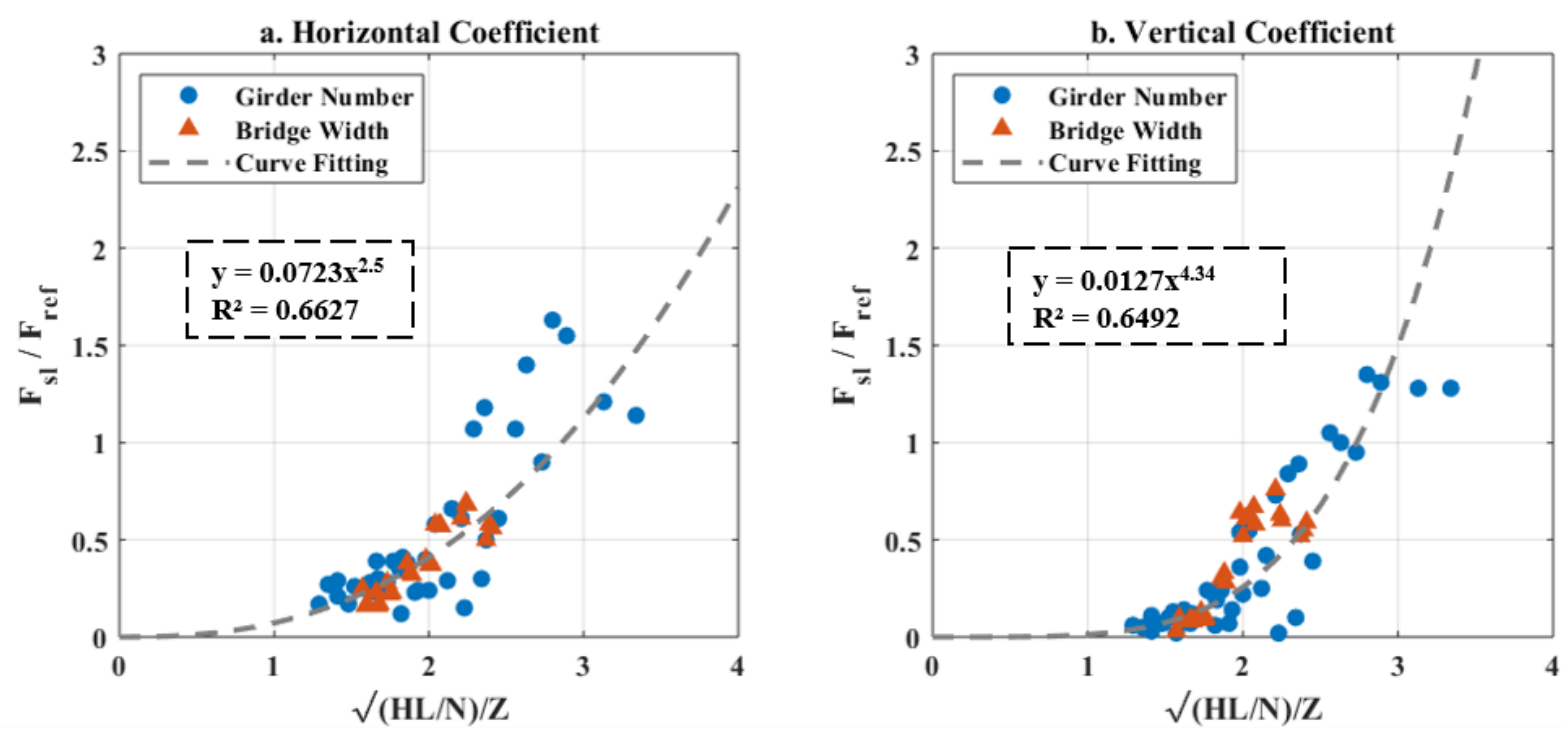

Figure 20. Regression analysis of the maximum wave forces predicted by the simulations over the reference wave force, as function of the unitless parameter $\sqrt{ }(\mathrm{HL} / \mathrm{N}) / \mathrm{Z}$.

\subsection{Accuracy of new method and comparison with existing equations}

Using the new simplified equations, the predicted maximum horizontal and vertical (uplift) wave forces are compared with the corresponding experimental and numerical results in Figure 21. The solid line represents a perfect matching, which means that the 
predicted wave forces are identical to the experimental or numerical results, and the data points above the solid line are overestimated values, while the ones below are underestimated ones. The $\pm 20 \%$ error range is also shown with dashed lines. The figure reveal that the predictions of the new method tend to fall within the $20 \%$ error range, while for the cases where the differences are larger, the simplified equations tends to over-predict the forces. Overall, the improved empirical equations demonstrate a good predictive capability of the wave loads.

While the comparison of the improved equations with experimental and numerical data gives an insight into its accuracy, it is also interesting to compare it with other empirical methods that are available in the literature. To this end, the authors will consider four popular predictive equations, including the ones developed in [6-9]. The detailed equations of these methods are shown in the Appendix of the manuscript (see eq. (A1)(A8)). Nonetheless, it is interesting to note that:

- The predictive equations of McConnell et al. [6], i.e. eq. (A1), (A2), divided the wave forces into several components, including the ones applied on the internal and the seaward (upstream) structural elements, and considering both the slab and the girders (beams) of jetties. The force on each component is a function of a reference hydrostatic force, without the explicit consideration of the impulsive component. The total wave forces are the summation of the wave forces on each structural element, which means that this set of equations considers the geometry of the deck.

- $\quad$ Douglass et al. [7] proposed predictive equations for the total applied wave forces on a coastal deck (see eq. (A3) - (A6)). These forces are calculated based on (i) a reference hydrostatic force and (ii) different coefficients that can be used to estimate either the "slowly-varying" forces or the total ones that include the impact component as well. Interestingly, the impact coefficient of the uplift forces was suggested to be three times larger than "slowly-varying" coefficient, revealing the high magnitude of the impact forces. Moreover, the equation for the uplift force is a function of the bridge width, while the horizontal force is a function of the number of girders $\mathrm{Ng}$. In the horizontal force equation the internal girders are contributing to the total force with a reduced coefficient of 0.4 relative to the offshore external girder (coefficient $=1$ ).

- McPherson [8] developed a different set of equations for the total wave loads applied on coastal bridge decks. In contrast to the equation of [7], the horizontal force was not a function of the internal girders, but just the external offshore and onshore girders, meaning the $\mathrm{Ng}$ did not influence the predicted force. On the other hand the uplift wave forces was distributed into the hydrostatic force $\left(F_{H}\right)$, buoyancy force $\left(F_{B}\right)$, the weight of overtopping water $\left(F_{W}\right)$ and the air-entrapment force $\left(F_{A}\right)$. In this method all the internal chambers were assumed to be filled with air up to $50 \%$ of their individual volume, which means that the total uplift was dependent on the volume of the chamber and consequently on the number of girders $\mathrm{Ng}$.

Figure 22 presents for three selected decks with two, four and six girders, the (i) predicted horizontal and uplift forces from the aforementioned available equations in the literature, and (ii) the improved method developed in this manuscript, together with the numerical and experimental results. For the Douglass et al [7] method, two sets of forces were calculated, i.e. with and without the impact component. Furthermore, since the current numerical results corresponded to coastal decks that allowed the air to escape from the sides, while the method of McPherson [8], was developed for decks with trapped air, two sets of equations were used for the prediction of the uplift forces, i.e. with and without consideration of the air-entrapment force $\left(F_{A}\right)$. 

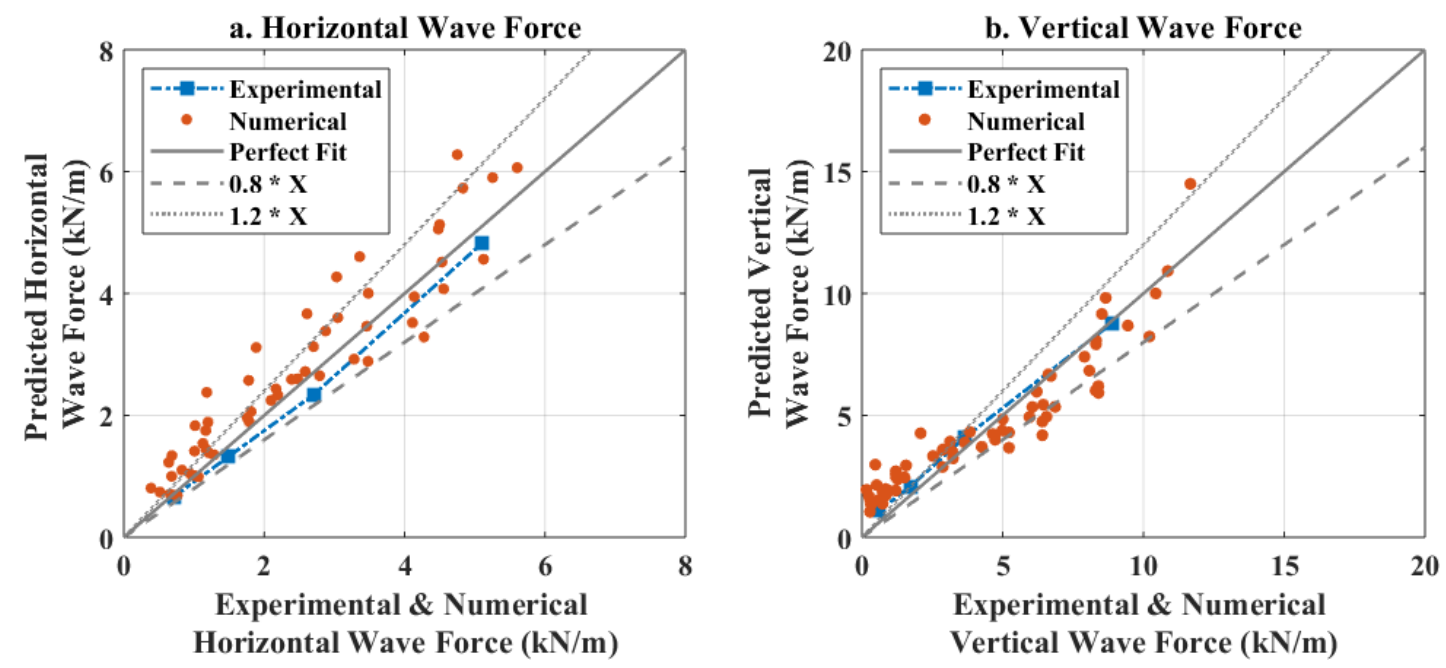

Figure 21. Comparisons of the maximum wave forces predicted by the new method with the numerical results and experimental measurements

Regarding the horizontal force, the new method gives overall the most accurate results for the three decks, although for the two largest heights in the case of a deck with $\mathrm{Ng}=2$ the equations of Azadbakht and Yim [9] give better predictions. For the majority of the decks, the horizontal force predicted by Douglass et al [7] under-predicts the actual force if the impact component is neglected and it over-predicts significantly if it is considered. On the other hand, the equation of McConnell et al [6] and McPherson [8] tend to over-predict significantly the horizontal force for most cases (e.g. by a factor of 3.8 and 7.22 respectively for the largest height), with the former one under-predicting the force only for $N g=2$.

In regards to the maximum uplift forces, the new method achieves the most accurate performance for the three decks with different $\mathrm{Ng}$, however, an observed issue is that it does not seem to be able to capture the change of slope observed in the numerical data when the wave height increased above a certain limit. The method of Douglass et al. [7] tends to over-predict the uplift force for most cases, even if the impact component is not considered, although in this case the predictions are closer to the numerical results. If the impact component is taken into account the over-prediction is very large. The equations of McPherson [8] over-predict significantly the uplift if the buoyancy of the trapped air is considered, but give more accurate results if the air is neglected, achieving especially very good predictions for decks with large number of girders. Furthermore, the equations developed by McConnell et al [6] and Azadbakht and Yim [9], seem to give overall reasonable estimations, with the former one being more accurate for decks with a small number of girders (e.g. $N g=2$ ) and the latter one for decks with a larger number of girders (e.g. $\mathrm{Ng}=6$ ). In summary, although some of the available equations in the literature can be quite accurate in estimating the horizontal and uplift forces for specific decks and wave heights, only the new method presented herein predicts consistently reasonable forces for the whole range of $\mathrm{Ng}$ and conditions, which makes sense since it was developed based on this wider range of cases.

Figure 23 shows the predicted forces from the aforementioned equations and the numerical results, but for the wider decks with respective lengths of $2.98 \mathrm{~m}(150 \% L)$ and $4.02 \mathrm{~m}(200 \% \mathrm{~L})$. In the horizontal direction the new method gives the most accurate predictions, followed by the method of Azadbakht and Yim [9] and the Douglass et al. [7], if the impact component is not considered in the latter case. When the impact is taken into account then the horizontal force is over-predicted by the latter method, especially for large wave heights. Furthermore, the empirical equations of McConnell et al [6] and McPherson [8] over-predict the horizontal forces, with the over-prediction increasing for wider decks. Regarding the vertical direction, the majority of the equations over-predict the uplift force, and their predictive capability is reduced as the deck width increases. The 
best overall predictions of the uplift force are achieved by the new method and the McPherson equations without the buoyancy force from the trapped air.

In a nutshell, the last two figures demonstrate that the new method developed herein achieves the most accurate prediction of the horizontal force for the majority of wave heights, decks with different number of girders ( $\mathrm{Ng}$ between two and six) and widths (e.g. exception is the $N g=2$ and the largest wave height, for which the new method over-predicts $F_{H}$ by $36 \%$ and the Azadbakht \& Yim equations predicts it better). In the vertical direction, the new method gives the best prediction of the uplift force for the decks with the baseline width and different number of girder $(\mathrm{Ng}=2-6)$, and one of the best predictions for the two wider decks (together with the McPherson (2008) method). Therefore, taking into account the capability of the simplified empirical methods in predicting both the horizontal and uplift forces for the whole range of geometries and conditions considered herein, the new method is the most accurate one, which is expected since it has been developed based on this wider range of conditions.
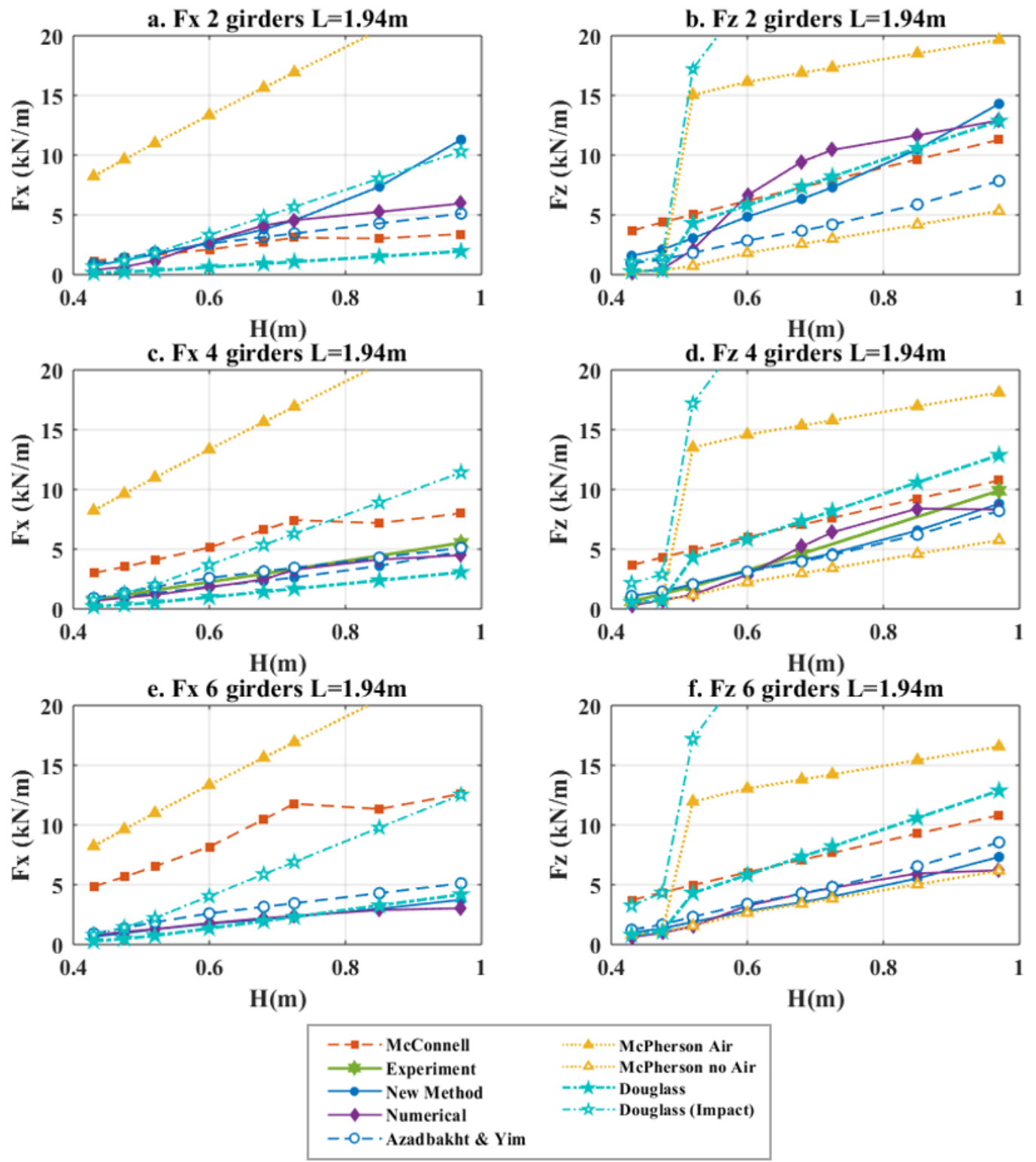

Figure 22. Comparisons of the maximum wave forces predicted by different methods with the numerical results and experimental measurements, for three decks with different number of girders ( $\mathrm{Ng}=2,4$ and 6$)$ 

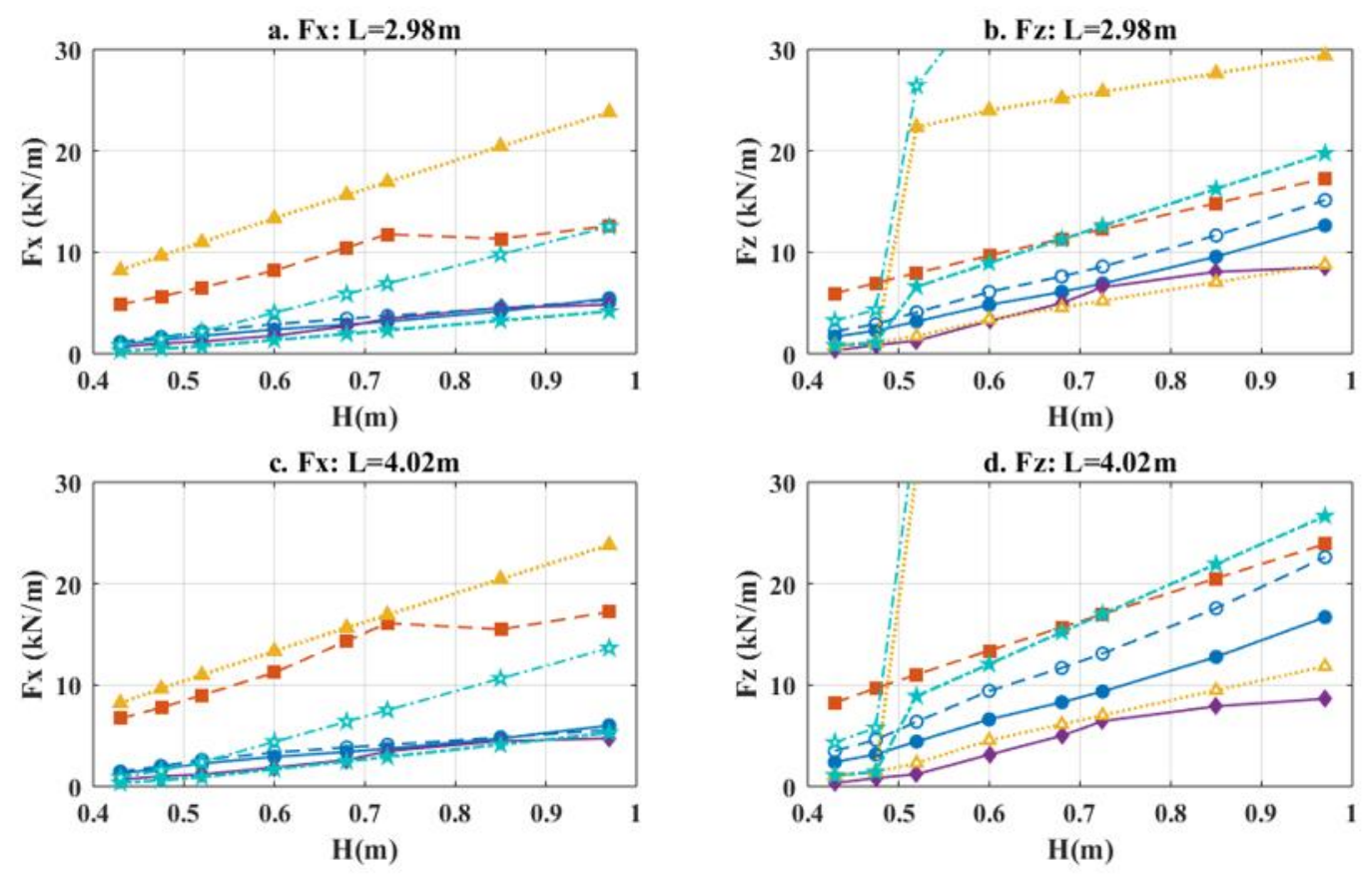

\begin{tabular}{|c|c|}
\hline $\begin{array}{l}-- \text { MeConnell } \\
\longrightarrow-\text { Experiment } \\
\longrightarrow-\text { New Method } \\
- \text { - Numerical } \\
\text { Azadbakht \& Yim }\end{array}$ & 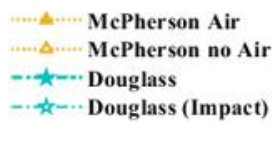 \\
\hline
\end{tabular}

Figure 23. Comparisons of the maximum wave forces predicted by different methods with the numerical results, for two decks with different widths $(150 \% \mathrm{~L}$ and $200 \% \mathrm{~L})$

Despite the promising performance of the new empirical equations for the specific range of conditions and deck geometries, it would be interesting to check in future studies its accuracy for hydrodynamic conditions and geometries outside the range investigated herein. For example, additional deck elevations, girder heights, and ratios of (deck width/girder height) should be considered in the future. Ideally, the deck dimensions, ratios of the (deck width/girder height) and number of girders $\mathrm{Ng}$ should be selected based on the actual design process of a superstructure (e.g. as prescribed in AASHTO LRFD [59]), which might require to change the height or thickness of girders when the $\mathrm{Ng}$ was changed (not considered herein). Furthermore, follow-up studies could investigate additional wave heights and different types of waves, such as, regular and random waves that will more realistically represent hurricane waves. Also, it would be interesting to investigate ways of expanding the method to cases of oblique wave impact on the deck, since the current version is limited only to the idealized scenario of a normal impact (i.e. 90 degrees angle between the direction of the deck length and the wave propagation). Other limitations of the current numerical investigation and predictive equations include: (i) the fact that it is applicable only to decks that do not have diaphragms and thus allow the air to escape from the sides, and (ii) the consideration of only rigid supports without any lateral, vertical or rotational flexibility that could potentially affect significantly the reaction forces as seen in previous studies (e.g. [16], [24], [34-36], [60]).

\section{Summary and Conclusions}

Using solitary waves to represent extreme wave conditions, the current study focuses on investigating the wave-induced loads on elevated coastal decks that allow the air to escape from the sides, such as, bridge decks with cross-frames. The aim is to advance the fundamental understanding of the role of the deck geometry, including the number of girders $(\mathrm{Ng})$ and the deck width $(L)$ on the wave loads that the structure has to sustain. To 
this end, an arbitrary Lagrangian-Eulerian (ALE) numerical method with a multi-phase compressible formulation is used and validated with large-scale experiments of wave impact on a representative coastal deck [19]. The experimental specimen of the open-girder deck, which was $3.45 \mathrm{~m}$ by $1.94 \mathrm{~m}$ in-plane, was simulated in a three-dimensional (3D) numerical model with a $0.25 \mathrm{~m}$ span length and $0.30 \mathrm{~m}$ flume width, in order to speed-up the calculations while allowing the trapped air to escape from the sides of the model as observed in the experiments.

The comparison of the numerical and experimental results demonstrated that the ALE method can capture with good accuracy the wave profiles in front of the coastal deck, as well as, the horizontal and vertical wave forces. Some differences were observed in the prediction of the tail and shape of the largest waves, which in turn affected the downward force. However, this was due to the fact that the length of the numerical flume was reduced relative to the experimental one in order to reduce the size of the model, meaning that the shoaling process and associated potential nonlinear transformation of the waves, was not simulated. This truncated hydrodynamic model was also capable of predicting reasonably the wave pressures applied on the girders and in the chambers below the deck, providing additional evidence of the validity of the numerical assumptions and the accuracy of the ALE method. Using the validated numerical model as a benchmark, a followup parametric investigation of different deck geometries with two, three, four, five and six girders (for the same deck width) and three different widths $(L, 1.5 L$ and $2 L$ ) was conducted. The numerical results revealed that:

- The effect of $\mathrm{Ng}$ on the total forces is dependent on the wave height $\mathrm{H}$. For small $\mathrm{H}$, the maximum horizontal and vertical forces increase with $\mathrm{Ng}$ at a relatively small rate, while for medium-to-large $H$ the increase of the $\mathrm{Ng}$ causes major reductions of the forces at a much larger rate. In fact, the five-girder deck has to withstand about $50 \%$ and $33 \%$ of the horizontal and uplift forces applied on the two-girder deck.

- For both the horizontal and uplift direction the $\mathrm{Ng}$ has an opposite effect on the quasistatic and slamming forces, which could potentially explain the complex role of $\mathrm{Ng}$ observed in previous studies [41], [51-52]. In fact, as $\mathrm{Ng}$ increases, the maximum values of the quasi-static forces increase nonlinearly with a slow rate, while the slamming forces decrease dramatically. Depending on the deck geometry, the latter forces can be twice as large as the former ones for the big waves and negligible for the small ones, which means that the effect of $\mathrm{Ng}$ on the total forces is governed by its effect on (i) the slamming forces when the wave height is large and $\mathrm{Ng}$ is small, (ii) the quasistatic ones when the wave is small, and (iii) both components for all other cases.

- The main reason for the generation of larger horizontal and uplift forces on the decks with a small $\mathrm{Ng}$ (i.e. 2,3) is the fact that the fluid particles accelerate after the initial impact on the offshore girder and propagate inside a long chamber that allows the fluid to increase its velocity further. This results in a more violent slamming on the onshore girder and deck slab that generates large impulsive pressures and forces. For a large $\mathrm{Ng}$ (e.g. 5, 6), the multiple girders and chambers (i) prevent the fluid from accelerating, (ii) cause the formation of unsynchronized eddies in each chamber that dissipate energy, and (iii) result in multiple but smaller loads on the deck due to the out-of-phase application of pressures on the consecutive structural elements.

- The increase of the bridge width (from $L$ to $1.5 L$ and $2 L$ ) increases the number of peaks in the force histories due to the additional girders and chambers, and tends to elongate the inundation process and duration of the applied forces. However, it has a minor-to-negligible effect on the maximum horizontal and uplift force. In the vertical direction, this can be attributed to the fact the maximum uplift tends to occur when the wave has inundated the three chambers (less than $100 \% L$ ), and after that the wave overtops the deck counter-acting any uplift pressures that might be generated in the additional chambers of the wider decks. Moreover, for very wide decks the wave cannot inundate the whole deck width, meaning that the maximum inundation and respective forces are limited by the wavelength. 
The last section of the current study focused on the development of a new simplified method for predicting the maximum solitary wave-induced loads on the aforementioned type of coastal decks. The new predictive equations: (i) include improved slamming coefficients that are a function of a new unitless parameter that is dependent on the number girders $\mathrm{Ng}$ (width of chamber), i.e. $\sqrt{H \frac{L}{N_{g}}} / Z$, and (ii) are limited by the ratio of $L_{\text {wave }} / L$ in the vertical direction. These new equations demonstrate a good predictive capability of the wave loads, with the most estimates falling within the $20 \%$ error range from the results of the numerical simulations. In the cases where the differences are larger, the simplified equations tend to over-predict the forces. Furthermore, comparison of the new method with four popular empirical methods available in the literature, showed that the new equations can achieve the highest accuracy for the range of wave conditions and deck geometries considered herein.

It must be noted that the presented findings and empirical equations are limited to the particular (i) hydrodynamic conditions and wave type, and (ii) deck elevations, geometries and type (e.g. open-girder with rigid connections and without trapped air). Future studies are encouraged to investigate the accuracy of the current work outside the range of the selected conditions and the need for further modifications, in order to quantify as realistically as possible the effects of storm and hurricane waves on coastal decks. Moreover, since the numerical results indicate the possibility to reduce the wave loads without increasing the number of girders too much (i.e. limit the construction material), future studies should explore the possibility for design optimization of elevated coastal decks, in order achieve safer and more sustainable infrastructure.

Author Contributions: Conceptualization, D.I.; methodology, D.I.; validation, T.X. and D.I.; formal analysis, T.X. and D.I.; investigation, T.X. and D.I.; resources, D.I.; data curation, T.X. and D.I.; writing-original draft preparation, T.X. and D.I.; writing - review and editing, D.I.; visualization, T.X. and D.I.; supervision, D.I.. All authors have read and agreed to the published version of the manuscript

Funding: This research received no external funding

Institutional Review Board Statement: Not applicable.

Informed Consent Statement: Not applicable.

Data Availability Statement: The numerical data presented in this study are available on request from the corresponding author.

Acknowledgments: The authors acknowledge prof. Ian Buckle from the University of Nevada, Reno and prof. Solomon Yim from Oregon State University for their major contribution in the experimental tests that were used as the benchmark of the validation study of this article, and the Engineering Computing Team at the University of Nevada, Reno for providing computational support and resources that have contributed to the research results reported within this paper.

Conflicts of Interest: The authors declare no conflict of interest.

\section{Appendix A}

This appendix will present the empirical wave load equations developed by previous studies [6-8].

McConnell et al [6]: The empirical equations for the decks and girders are given as Horizontal:

Vertical:

$$
F_{h}=a /\left[\frac{\left(\eta_{\max }-c_{1}\right)}{H_{s}}\right]^{b} F_{h}^{*} ;
$$

$$
F_{v}=a /\left[\frac{\left(\eta_{\max }-c_{1}\right)}{H_{S}}\right]^{b} F_{v}^{*} ;
$$


$F_{h}^{*}$ and $F_{v}^{*}$ are basic wave forces calculated by the hydrostatic pressure of the height of the incoming waves and multiplied by the wet projection area of both horizontal and vertical elements. And $a$ and $b$ are parameters associated with the structural elements (girders and decks) and the element locations (seaward or internal).

Douglass et al. [7]: The empirical equations for estimating the slowly-varying wave forces on an elevated bridge deck, are:

Vertical force:

Horizontal force:

$$
F_{v}=c_{v-v a} F_{v}^{*}
$$

$$
F_{h}=\left[1+c_{r}(N-1)\right] c_{h-v a} F_{h}^{*}
$$

Where, $F_{v}^{*}=\gamma\left(\Delta z_{v}\right) A_{v}$ and $F_{h}^{*}=\gamma\left(\Delta z_{h}\right) A_{h}$ are reference forces calculated based on the hydrostatic pressure. $c_{v-v a}$ and $c_{h-v a}$ are empirical coefficients which are suggested to be 1 . The horizontal force is the combination of the wave forces on each bridge girder, where $\mathrm{N}$ is the number of girders and $c_{r}$ is a reduction factor for internal girders, which is suggested to be 0.4. Additionally, the previous equations can be expanded to include the impact forces as well by using the additional coefficients: $c_{v-i m}$ and $c_{h-i m}$, as shown in equations (A5) and (A6). These coefficients are equal to 6 and 3, respectively:

Vertical force:

Horizontal force:

$$
F_{v}=\left(c_{v-v a}+c_{v-i m}\right) F_{v}^{*}
$$

$$
F_{h}=\left\{\left[1+c_{r}(N-1)\right] c_{h-v a}+c_{h-i m}\right) F_{h}^{*}
$$

McPherson [8] proposed empirical equations that predict the total horizontal and uplift forces and are a function of the bridge geometry, as shown below:

$$
\begin{gathered}
F_{H}=F_{\text {Hydrostatic_upstream }}-F_{\text {Hydrostatic_downstream }} \\
F_{v}=F_{H}-F_{W}+F_{B}+F_{A}=\gamma \delta_{z} A_{\text {wet }}-F_{W}+\gamma V_{\text {Bridge }}+(N-1) 0.5 \gamma \delta_{G} A_{G}
\end{gathered}
$$

In this method the horizontal wave forces consider the hydrostatic wave pressure only on the upstream and downstream girders, which depend only on the wave height and deck height. Regarding the uplift force, it consists of the hydrostatic force $\left(F_{H}\right)$, buoyancy force $\left(F_{B}\right)$, air-entrapment force $\left(F_{A}\right)$ and the weight of the overtopping water $\left(F_{W}\right)$. In this equation, $A_{G}$ represents the area of an individual chamber, and $\mathrm{N}$ represents the number of girders.

\section{References}

1. Mondal, G.; Rai, D.C. Performance of harbour structures in Andaman Islands during 2004 Sumatra earthquake. Eng. Struct. 2008, 30, 174-182. https://doi.org/10.1016/j.engstruct.2007.03.015

2. Padgett, J.; DesRoches, R.; Nielson, B.; Yashinsky, M.; Kwon, O.S.; Burdette, N.; Tavera, E. Bridge damage and repair costs from Hurricane Katrina. J. Bridge Eng. 2008, 13(1), pp.6-14. https://doi.org/10.1061/(ASCE)10840702(2008)13:1(6)

3. Maruyama, Y.; Kitamura, K.; Yamazaki, F. Estimation of tsunami-inundated areas in Asahi City, Chiba Prefecture, after the 2011 Tohoku-Oki Earthquake. Earthq. Spectra. 2013. 29(S1), S201-217. https://doi.org/10.1193/1.4000123

4. Maruyama, K.; Tanaka, Y.; Kosa, K.; Hosoda, A.; Arikawa, T. Evaluation of tsunami force acting on bridge girders. Proc., 13th East Asia-Pacific Conf. on Structural Engineering and Construction, American Concrete Institute, USA, Farmington Hills, MI, 2013.

5. Williams, J. H.; Wilson, T. M.; Horspool, N.; Paulik, R.; Wotherspoon, L.; Lane, E. M.; Hughes, M. W. Assessing transportation vulnerability to tsunamis: utilising post-event field data from the 2011 Tōhoku tsunami, Japan, and the 2015 Illapel tsunami, Chile, Nat. Hazards Earth Syst. Sci. 2020, 20, 451-470, https://doi.org/10.5194/nhess20-451-2020. 
6. McConnell, K.; W. Allsop; I. Cruickshank. Piers, jetties, and related structures exposed to waves: Guidelines for hydraulic loadings. Thomas Telford Ltd: London, 2004.

7. Douglass, S. L.; Q. Chen; J. M. Olsen; B. L. Edge; D. Brown. Wave forces on bridge decks. Washington, DC: U.S. Dept. of Transportation, Federal Highway Administration, Office of Bridge Technology. 2006.

8. McPherson, R. L. Hurricane-induced Wave and Surge Forces on Bridge Decks. M.S. thesis, Texas A\&M University., College Station, TX, 2008.

9. Azadbakht, M.; S. C. Yim. Simulation and estimation of tsunami loads on bridge superstructures. J. Waterway, Port, Coastal, Ocean Eng. 2015, 141 (2): 04014031. https://doi.org/10.1061/(ASCE)WW .1943-5460.0000262

10. Xiang, T.; Istrati, D.; Yim, S. C.; Buckle, I. G.; Lomonaco, P. Tsunami Loads on a Representative Coastal Bridge Deck: Experimental Study and Validation of Design Equations. J. Waterway, Port, Coastal, Ocean Eng. 2020, 146(5), 04020022. https://doi.org/10.1061/(ASCE)WW.1943-5460.0000560.

11. El Ghamry; Osman, A. Wave forces on a dock. Technical Rep. No. HEL-9-1, Hydraulic Engineering Laboratory, Wave Research Projects, Hydraulic Engineering Laboratory, Institute of Engineering Research, Univ. of California, Berkeley, CA., 1963.

12. French, J. A. Wave uplift pressures on horizontal platforms. Ph.D. Dissertation, California Institute of Technology, Pasadena, CA., 1970.

13. Overbeek, J.; Klabbers, I.M. Design of jetty decks for extreme vertical wave loads. Ports Conference. Norfolk, Virginia, United States, April 29-May 2, 2001.

14. Wang, H. Water wave pressure on horizontal plate. J. Hydr. Div. 1970, 96(10), 1997-2017. https://doi.org/10.1061/JYCEAJ.0002724

15. Robertson, I. N.; Riggs, H. R.; Yim, S. C.; Young, Y. L. Lessons from Hurricane Katrina storm surge on bridges and buildings. J. Waterway, Port, Coastal, Ocean Eng. 2007, 133(6), 463-483. https://doi.org/10.1061/(ASCE)0733950X(2007)133:6(463)

16. Bradner, C. Large-scale laboratory observations of wave forces on a highway bridge superstructure. M.S. thesis, Oregon State Univ., Corvallis, OR, 2008.

17. Guo, A.; Fang, Q.; Li, H. Analytical solution of hurricane wave forces acting on submerged bridge decks. Ocean Eng. 2015, 108, 519-528. https://doi.org/10.1016/j.oceaneng.2015.08.018

18. Nakamura, T.; Sawa, Y.; Mizutani, N. Study on the evaluation of temporal change in horizontal and vertical tsunami forces acting on a bridge superstructure, Coast. Eng. J. 2016, 58:4, 1640020-1-1640020-27, https://doi.org/10.1142/S0578563416400209

19. Istrati, D. Large-Scale Experiments of Tsunami Inundation of Bridges including Fluid-Structure-Interaction. Ph.D. Dissertation. University of Nevada, Reno, 2017. https://scholarworks.unr.edu//handle/11714/2030

20. Istrati, D.; Buckle, I.G.; Itani, A.; Lomonaco, P.; Yim S. Large-scale FSI experiments on tsunami-induced forces in bridges 16th World Conf. Eq. Eng., Santiago, Chile, Jan. 9-13, 2017, https:/www.wcee.nicee.org/wcee/article/16WCEE/WCEE2017-2579.pdf (Accessed Oct. 24, 2021)

21. Huang, B.; Zhu, B.; Cui, S.; Duan, L.; Zhang, J. Experimental and numerical modelling of wave forces on coastal bridge superstructures with box girders, Part I: Regular waves. Ocean Eng., 2018, 149, 53-77.

https://doi.org/10.1016/j.oceaneng.2017.11.046

22. Denson, K.H. Wave forces on causeway-type coastal bridges. NASA STI/Recon Technical Report N. 79 1978.

23. Istrati, D.; Buckle, I.G.; A., Lomonaco, P.; Yim, S. Deciphering the Tsunami Wave Impact and Associated Connection Forces in Open-Girder Coastal Bridges. J. Mar. Sci. Eng. 2018, 6(4), 148. https://doi.org/10.3390/jmse6040148

24. Cai, Y.; Agrawal, A.; Qu, K., and Tang, H.S. Numerical Investigation of Connection Forces of a Coastal Bridge Deck Impacted by Solitary Waves. J. Bridge Eng. 2018, 23(1), 04017108. https://doi.org/10.1061/(ASCE)BE.19435592.0001135

25. AASHTO (2008), Guide Specifications for Bridges Vulnerable to Coastal Storms, American Association of State Highway and Transportation Officials (AASHTO)

26. Istrati, D.; Buckle, I. Role of trapped air on the tsunami-induced transient loads and response of coastal bridges. Geosciences, 2019, 9(4), 191. https://doi.org/10.3390/geosciences9040191

27. Deng, L.; Yang, W.; Li, Q.; Li, A. CFD investigation of the cap effects on wave loads on piles for the pile-cap foundation. Ocean Eng., 2019, 183, 249-261. https://doi.org/10.1016/j.oceaneng.2019.05.004

28. Xu, B.; Wei, K.; Qin, S.; Hong, J. Experimental study of wave loads on elevated pile cap of pile group foundation for sea-crossing bridges. Ocean Eng. 2020, 197, 106896. https://doi.org/10.1016/j.oceaneng.2019.106896

29. Do, T. A.; Nguyen, T. H.; Nguyen, H. M.; Tran, N. D.; Nguyen, L. N. Evaluation of dynamic impact of flow with bridge pier using smoothed particle hydrodynamics method. Prog. Comput. Fluid Dyn. 2020, 20(6), $332-348$. http://www.inderscience.com/offer.php?id=111401 
30. Qeshta, I. M.; Hashemi, M. J.; Gravina, R.; Setunge, S. Review of resilience assessment of coastal bridges to extreme wave-induced loads. Eng. Struct, 2019, 185, 332-352. https://doi.org/10.1016/j.engstruct.2019.01.101

31. Webb, B. M.; Cleary, J. C. Drag-Induced Displacement of a Simply Supported Bridge Span during Hurricane Katrina. J. Perform. Constr. Facil. 2019, 33(4), 04019040. https://doi.org/10.1061/(ASCE)CF.1943-5509.0001305

32. Lomonaco, P.; Istrati, D.; Maddux, T.; Buckle, I.G.; Yim, S.; Xiang, T. Large-scale testing of tsunami impact forces on bridges. Proc. 6th Intl Conf on the Application of Physical Modelling in Coastal and Port Engineering and Science (Coastlab16), Ottawa, Canada, May 10-13, 2016, DOI: 10.13140/RG.2.1.5184.2160.

33. Huang, W.; Xiao, H. Numerical modeling of dynamic wave force acting on Escambia bay bridge deck during Hurricane Ivan. J. Waterway, Port, Coastal, and Ocean Eng. 2009, 135(4), 164-175. https://doi.org/10.1061/(ASCE)0733-950X(2009)135:4(164)

34. Istrati, D.; Buckle, I. G. Effect of fluid-structure interaction on connection forces in bridges due to tsunami loads. In Proc 30th US-Japan Bridge Engineering Workshop, Washington DC, United States. 2014. https://www.pwri.go.jp/eng/ujnr/tc/g/pdf/30/30-10-2_Buckle.pdf (Accessed Oct. 20, 2021)

35. Xu, G.; Cai, C. S. Numerical simulations of lateral restraining stiffness effect on bridge deck-wave interaction under solitary waves. Eng. Struct. 2015, 101, 337-351. https://doi.org/10.1016/j.engstruct.2015.07.031

36. Matamoros, A.; Testik, F.; Nasouri, R.; Montoya, A. Coastal Bridges under Hurricane Stresses along the Texas and Louisiana Coast, Transportation Consortium of South-Central States, Dec. 2018. https://digitalcommons.lsu.edu/transet_pubs/29/

37. Greco, F.; Lonetti, P.; Blasi, P. N. Vulnerability analysis of bridge superstructures under extreme fluid actions. J. Fluids Struct. 2020, 93, 102843. https://doi.org/10.1016/j.jfluidstructs.2019.102843

38. Hasanpour, A.; Istrati, D. Reducing extreme flooding loads on essential facilities via elevated structures, ASCE Lifelines Conference 2021-22, University of California, Los Angeles, 2021.

39. Wei, Z. P.; Dalrymple, R. A. Numerical study on mitigating tsunami force on bridges by an SPH model. J. Ocean Eng. Mar. Energy, 2016, 2(3), 365-380. https://doi.org/10.1007/s40722-016-0054-6

40. Aristodemo, F.; Tripepi, G.; Meringolo, D.D.; Veltri, P. Solitary wave-induced forces on horizontal circular cylinders: Laboratory experiments and SPH simulations. Coast. Eng. 2017, 129, 17-35, https://doi.org/10.1016/j.coastaleng.2017.08.011.

41. Sarfaraz, M.; Pak, A. SPH Numerical Simulation of Tsunami Wave Forces Impinged on Bridge Superstructures, Coastal Eng. 2017, 121, 145-157. https://doi.org/10.1016/j.coastaleng.2016.12.005

42. Zhu, M.J.; Elkhetali, I.; Scott, M.H. Validation of OpenSees for tsunami loading on bridge superstructures. J. Bridge Eng. 2018, 23(4), 04018015. https://doi.org/10.1061/(ASCE)BE.1943-5592.0001221

43. Hasanpour, A.; Istrati, D.; Buckle, I. Coupled SPH-FEM Modeling of Tsunami-Borne Large Debris Flow and Impact on Coastal Structures. Journal of Marine Science and Engineering, 9(10), 1068. https://doi.org/10.3390/jmse9101068

44. Bozorgnia, M.; Lee, J. J. Computational fluid dynamic analysis of highway bridges exposed to hurricane waves. Proc., 33rd Conf. on Coastal Engineering, Coastal Engineering Research Council, ASCE, Reston, VA, 2012. https://doi.org/10.9753/icce.v33.waves.70

45. Crowley, R.; Robeck C.; Dompe, P. A three-dimensional computational analysis of bridges subjected to monochromatic wave attack. J. Fluids Struct. 2018, 79, 76-93. https://doi.org/10.1016/j.jfluidstructs.2018.02.001

46. Istrati, D.; Buckle, I. G.; Lomonaco, P.; Yim, S.; Itani, A. Tsunami induced forces in bridges: large-scale experiments and the role of air-entrapment. Coast. Eng. Proc. 2017, (35), 30-30. https://doi.org/10.9753/icce.v35.structures.30

47. Motley, M. R.; Wong, H. K.; Qin, X.; Winter, A. O.; Eberhard, M. O. Tsunami-induced forces on skewed bridges. J. Waterway, Port, Coastal, Ocean Eng. 2016, 142(3), 04015025. https://doi.org/10.1061/(ASCE)WW.19435460.0000328

48. Istrati, D.; Buckle, I. G. Tsunami Loads on Straight and Skewed Bridges-Part 1: Experimental Investigation and Design Recommendations (No. FHWA-OR-RD-21-12). Oregon. Dept. of Transportation. Research Section. 2021. https://rosap.ntl.bts.gov/view/dot/55988

49. Istrati, D.; Buckle, I.G. Tsunami Loads on Straight and Skewed Bridges-Part 2: Numerical Investigation and Design Recommendations (No. FHWA-OR-RD-21-13). Oregon. Dept. of Transportation. Research Section, 2021. https://rosap.ntl.bts.gov/view/dot/55947

50. Istrati, D.; Hasanpour, A.; Buckle, I.G. Numerical investigation of tsunami-borne debris damming loads on a coastal bridge. 17th World Conference of Earthquake Engineering, Sendai, Japan, Sept. 27 - Oct. 2, 2021.

51. Hayatdavoodi, M.; Seiffert, B.; Ertekin, R.C. Experiments and computations of solitary-wave forces on a coastalbridge deck. Part II: Deck with girders, Coast. Eng. 2014, 88, 210-228.

https://doi.org/10.1016/j.coastaleng.2014.02.007 
52. Moideen, R.; Behera, M.R.; Kamath, A.; Bihs, H. Effect of Girder Spacing and Depth on the Solitary Wave Impact on Coastal Bridge Deck for Different Airgaps, J. Mar. Sci. Eng. 2019, 7(5), 140. https://doi.org/10.3390/jmse7050140

53. Hallquist, J.O. LS-DYNA theory manual. Liverm. Softw. Technol. Corp. 2006, 3, $25-31$.

54. Souli, M.; Benson, D.J. Arbitrary Lagrangian Eulerian and Fluid-Structure Interaction: Numerical Simulation. John Wiley \& Sons. 2010.

55. Takahashi, S.; Tanimoto, K.; Miyanaga, S. Uplift wave forces due to compression of enclosed air layer and their similitude low. Coast. Eng. Jpn. 1985, 28, 191-206. https://doi.org/10.1080/05785634.1985.11924415

56. Cuomo, G.; Shimosako, K. I.; Takahashi, S. Wave-in-deck loads on coastal bridges and the role of air. Coast. Eng. 2009, 56(8), 793-809. https://doi.org/10.1016/j.coastaleng.2009.01.005

57. Hayatdavoodi, M.; Treichel, K.; Ertekin, R. Parametric study of nonlinear wave loads on submerged decks in shallow water. J. Fluids Struct. 2019, 86. 266-289. https://doi.org/10.1016/j.jfluidstructs.2019.02.016

58. Goring, D. G. Tsunamis-The propagation of long waves on to a shelf. Ph.D. Dissertation, California Institute of Technology, Pasadena, California, 1979.

59. AASHTO (2017), LRFD Bridge Design Specifications. $8^{\text {th }}$ ed., American Association of State Highway and Transportation Officials (AASHTO), 2007.

60. Istrati, D.; Buckle, I.; Lomonaco, P.; Yim, S.; Itani, A. Large-scale experiments of tsunami impact forces on bridges: The role of fluid-structure interaction and air-venting. Proceedings of the 26th International Ocean and Polar Engineering Conference. Rhodes, Greece, 2016. 